Review

\title{
Nanostructured Electrode Materials for Electrochemical Capacitor Applications
}

\section{Hojin Choi ${ }^{1}$ and Hyeonseok Yoon ${ }^{1,2, *}$}

1 Department of Polymer Engineering, Graduate School, Chonnam National University, 77 Yongbong-ro, Buk-gu, Gwangju 500-757, Korea; E-Mail: iyzvnzzang@gmail.com

2 School of Polymer Science and Engineering, Chonnam National University, 77 Yongbong-ro, Buk-gu, Gwangju 500-757, Korea

* Author to whom correspondence should be addressed; E-Mail: hyoon@chonnam.ac.kr; Tel.: +82-62-530-1778; Fax: +82-62-530-1779.

Academic Editor: Jiye Fang

Received: 1 April 2015 / Accepted: 27 May 2015 / Published: 2 June 2015

\begin{abstract}
The advent of novel organic and inorganic nanomaterials in recent years, particularly nanostructured carbons, conducting polymers, and metal oxides, has enabled the fabrication of various energy devices with enhanced performance. In this paper, we review in detail different nanomaterials used in the fabrication of electrochemical capacitor electrodes and also give a brief overview of electric double-layer capacitors, pseudocapacitors, and hybrid capacitors. From a materials point of view, the latest trends in electrochemical capacitor research are also discussed through extensive analysis of the literature and by highlighting notable research examples (published mostly since 2013). Finally, a perspective on next-generation capacitor technology is also given, including the challenges that lie ahead.
\end{abstract}

Keywords: nanomaterials; electrochemical capacitors; electric double-layer capacitors (EDLCs); pseudocapacitors; hybrid capacitors

\section{Introduction}

Electrochemical capacitors are a special class of electric energy storage devices that are based on nonfaradaic and/or faradaic charging/discharging at the interface between an electrode and an electrolyte [1,2]. In other words, they take advantage of ion adsorption and redox reactions to store 
electric energy in the electrode. They can complement or replace batteries used in electric energy storage devices and harvesting applications when high power delivery or uptake is required. The different properties of each type of electrochemical capacitor impart unique characteristics to such devices and enable their unique applications [3]. Two primary attributes of an electrochemical capacitor are its energy and power density, both of which are mostly expressed as a quantity per unit weight. Since the energy stored in electrochemical capacitors is related to the charge arising from the potential difference at each interface, especially in the case of nonfaradaic charge storage, they can offer more rapid charge/discharge rates as compared with batteries, whereas their energy density is lower than that of batteries [4]. Many researchers have made an effort to improve the energy density while maintaining high power density. Current research on electrochemical capacitors can be categorized into three device types: electric double-layer capacitors (EDLCs), pseudocapacitors, and hybrid capacitors [5].

In most cases, EDLCs are based on porous carbon electrode materials. EDLCs are often referred to as supercapacitors or ultracapacitors that electrostatically store the charge by using reversible adsorption of the electrolyte ions onto electrochemically stable, high-surface-area carbonaceous electrodes. The specific surface area of EDLCs is enlarged by making the bulk of the carbon material porous [6]. In principle, the main requirements for EDLC electrodes include: (i) fast charge/discharge rate; (ii) large potential window; (iii) high conductivity; and (iv) large effective surface area [7,8].

Pseudocapacitive materials show fast redox reactions during the charge/discharge process at their surface. The fact that charge storage is based on a redox process means that pseudocapacitors have some battery-like behavior (faradaic reaction) in their charge/discharge process [9,10]. Therefore, pseudocapacitors show higher capacitances than EDLCs, although they have somewhat slower charge/discharge rates than EDLCs. Pseudocapacitance is typically shown by materials such as conducting polymers and transition metal oxides. The interest is increasing in the development of improved materials for pseudocapacitors. To improve the capacitance of pseudocapacitors, four key factors are required: (i) doping of the conducting polymer to increase the redox state and conductivity; (ii) high charge/discharge rate; (iii) high surface area for the redox reaction; and (iv) a wide potential window [11,12].

Hybrid capacitors comprising EDLCs and pseudocapacitors combine their advantages, namely high energy and power densities $[13,14]$. The charge storage mechanisms in such devices are a combination of purely electrostatic adsorption-desorption phenomenon at the nonfaradaic electrode and a reversible faradaic reaction at the electrode. To achieve high energy density, hybrid capacitor systems comprising redox materials have been actively researched and developed in recent years [15]. Both EDLCs and pseudocapacitors are essential for fabricating high-performance hybrid capacitors. Electrochemical capacitors consist of electrolytes, separators, binders, and electrode materials. Here, we focus on the nanostructured electrode materials for use in the three different types of electrochemical capacitors, i.e., EDLCs, pseudocapacitors, and hybrid capacitors. The latest important works and achievements in electrochemical capacitor research are highlighted to provide information on what material factors are critical in determining the performance of electrochemical capacitors. We will mainly cover studies that have been conducted over the last few years, with major emphasis placed on the literature from 2013 to the present day. Lastly, future trends in the research field will be discussed, along with remaining technical challenges. 


\section{EDLC Materials}

Carbon materials are considered prospective electrode materials for industrialization. The advantages of carbon materials include large specific surface area, good electronic conductivity, and high chemical stability [16]. The charge storage mechanism of carbon-based electrode materials mostly conforms to that of EDLCs. The important factors influencing their electrochemical performance are specific surface area, pore-size distribution, pore shape and structure, electrical conductivity, and surface functionality. Among these, specific surface area and pore-size distribution are the two most important factors affecting the performance of EDLCs [17].

\subsection{Porous Carbon}

To realize the enhanced performance that stems from increasing the surface area of electrode materials, the pore size of the materials should be limited to the range of subnanometers to a few nanometers [18]. Extensive research has been conducted on developing porous structures [19]. The small pore sizes of carbon materials result in large specific surface areas. However, at a certain, optimal pore size, the effective surface area of the double layer is maximized while maintaining the optimal ion exchange with the electrolyte [20]. For example, a colloidal crystal templating method was optimized for the synthesis of three-dimensionally ordered mesoporous (3DOm) carbon with a well-defined geometry, a three-dimensional (3D) interconnected pore structure, and tunable pore sizes of $8-40 \mathrm{~nm}$ (Figure 1) [21]. To achieve precise control over the pore sizes in the carbon products, parameters were established for direct syntheses or seed growth of monodispersed silica nanospheres of specific sizes [22]. The 3DOms exhibited higher capacitance than conventional porous carbon electrodes. Moreover, using an ionic liquid as an electrolyte resulted in an increased cell voltage, which in turn enhanced the power density of the electrode [23].

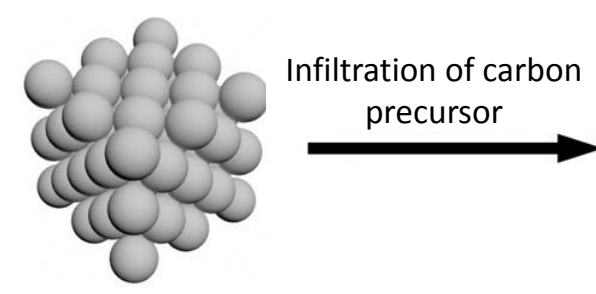

Silica template

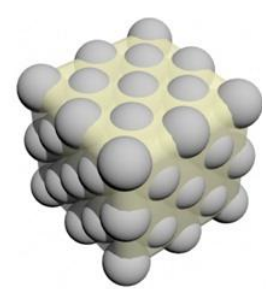

Silica-polymer composite
1) Pyrolysis $900{ }^{\circ} \mathrm{C}, 6 \mathrm{~h}$

2) Silica etching

Figure 1. Schematic of fabrication of three-dimensionally ordered mesoporous (3DOm) carbon. With permission from [21]; Copyright 2013, American Chemical Society.

These porous carbon materials have a synergistic effect when used in conjunction with other carbon materials [24]. A judicious combination of porous carbon and so-called nanocarbons, such as graphene [25], carbon nanotubes (CNTs) [26], and carbon nanofibers (CNFs) [27], could improve the capacitive performance based purely on the principle of an electrochemical double layer.

High-surface-area carbon nanotube (CNT)/microporous carbon composite materials were prepared for EDLC electrodes [28]. All-carbon-based CNT/microporous carbon core-shell nanocomposites have 
a high-surface-area microporous carbon shell. Therefore, these CNT/microporous carbon core-shell nanocomposites are promising electrode materials for EDLCs.

In another case, porous carbon-CNT-graphene ternary all-carbon foams were obtained through multicomponent surface self-assembly of graphene oxide (GO)-dispersed pristine CNTs (GOCs) supported on a commercial sponge [29]. The GO acted as a "surfactant" that dispersed the CNTs, thereby preserving their excellent electronic structure and preventing the aggregation of graphene, which resulted in an overall improvement of the conductivity. The fabrication of 3D hierarchically porous carbon-CNT-graphene ternary all-carbon foams (3D-HPCFs) is illustrated in Figure 2. The large number of high-surface-area mesopores promotes ion transport/charge storage.

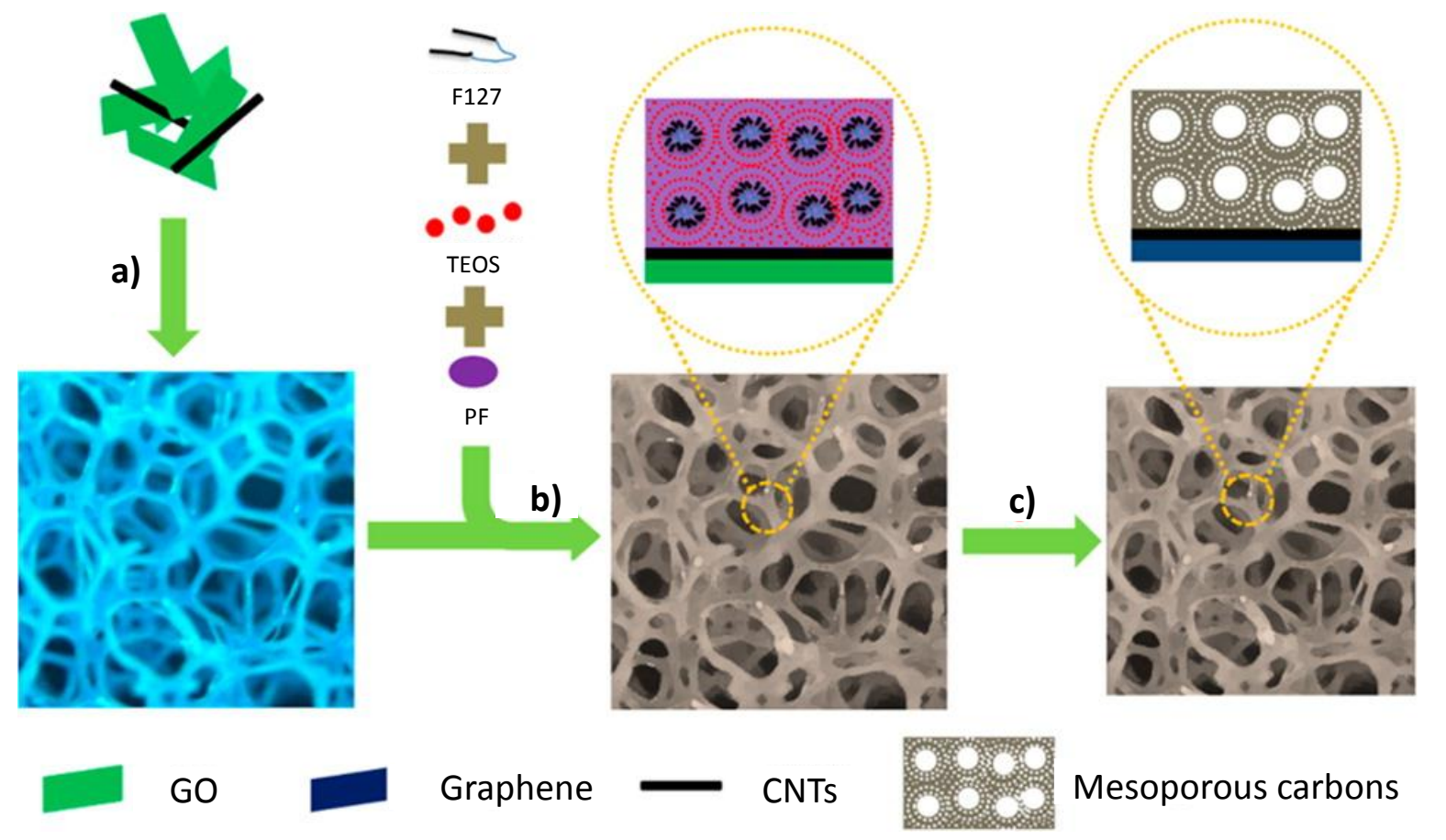

Figure 2. Fabrication of 3D hierarchically porous carbon-CNT-graphene ternary all-carbon foams (3D-HPCFs): (a) Impregnating sponge into the GOC solution; (b) Impregnating the resulting GOC/commercial sponge into a multicomponent ethanol solution of F127, phenol-formaldehyde resol, and tetraethoxysilane (TEOS) for self-assembly; (c) Carbonization and subsequent etching removal of $\mathrm{SiO}_{2}$ from TEOS. With permission from [29]; Copyright 2014, American Chemical Society.

\subsection{CNFs, CNTs, and Graphene}

Graphene has a maximum theoretical specific surface area of $c a .2600 \mathrm{~m}^{2} \cdot \mathrm{g}^{-1}$, which is twice that of single-walled CNTs and substantially higher than those of most carbon black and activated carbons [30]. Graphene is a unique and attractive electrode material owing to its atom-thick two-dimensional (2D) structure and excellent properties. However, graphene sheets easily form irreversible agglomerates and restack to the graphitic structure. To overcome this problem, graphene can be hybridized with CNTs, CNFs, and porous carbon. Various carbon hybrids have been fabricated by electrospinning followed by heat treatment [31], since electrospinning can readily create multicomponent nanofibers as the carbon precursor [32]. Graphene nanoribbon (GNR)/carbon composite nanofibers have been prepared by 
electrospinning from polyacrylonitrile (PAN)-containing GO nanoribbons (GONRs) and successive twisting and carbonization (Figure 3) [33].

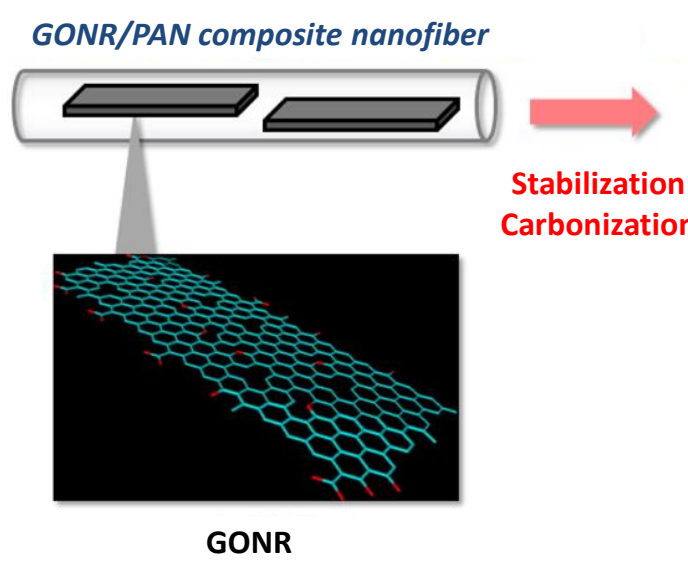

GNR/carbon composite nanofiber

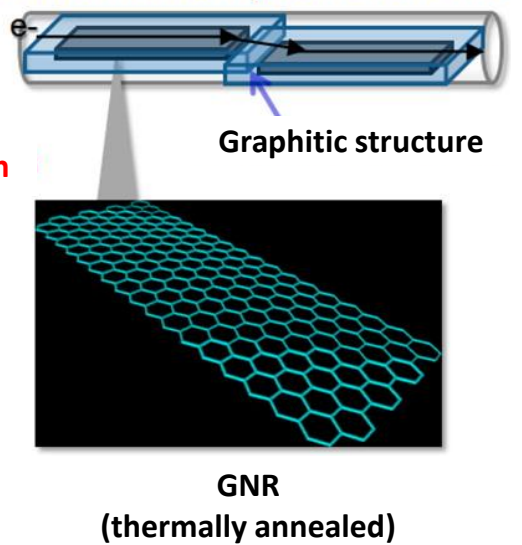

Figure 3. Schematic of the fabrication process of graphene nanoribbon (GNR)/carbon nanofiber (CNF) via carbonization. With permission from [33]; Copyright 2013, American Chemical Society.

Many studies have shown that highly oriented CNFs have a large surface area and excellent electrical properties [34]. PAN-containing GONR nanocomposites also become highly oriented during electrospinning. In addition, GONRs have been converted to an all-carbon material, GNR/CNF, by carbonization [35]. Both the graphene ribbons and CNFs exhibit high performance as electrochemical capacitors; it is expected that the structural synergistic effect would further improve this performance. Various methods of fabricating these graphene fiber materials have been investigated. Graphene-coated nanotube aerogels, a type of graphene fiber material, have been developed by coating the nodes of an isotropic single-wall carbon nanotube network within an aerogel with a few layers of graphene. These graphene-based CNT and CNF materials are especially important for textile-enabled materials and devices. They can also act as the building blocks for forming 2D and 3D macroscopic structures for EDLCs [36,37]. The use of CNFs and CNTs has further enhanced the properties of microelectrochemical capacitors, thereby enabling the fabrication of flexible and adaptable devices [38].

Many researchers have reported on combinations of CNTs, CNFs, metals, and graphene. CNTs and CNFs are connected to the graphene layer through covalent bonds, leading to seamless, high-quality carbon material-graphene-metal interfaces [39]. Ternary hybrid nanostructures consisting of CNFs, manganese oxide (MnO), and graphene were recently fabricated, as shown in Figure 4. The metal oxide $\mathrm{MnO}$ is a pseudocapacitive element, which will be discussed in a subsequent section. MnO-decorated CNFs (MCNFs) were dispersed in an aqueous solution containing isolated GO sheets exfoliated from oxidized graphite. GO sheets are highly dispersible in aqueous solution owing to the oxygen-containing functional groups, and they have high affinity with CNFs because of their similar chemical structures. Thus, MCNFs were readily wrapped with GO sheets to yield a 3D nanohybrid architecture. Afterwards, GO was converted to reduced graphene oxide (RGO) by using hydrazine. Intercalated MCNFs improved the conductivity of the MCNF/RGO nanocomposite and facilitated ion diffusion by increasing the spacing between the graphene sheets. The RGO sheet is considered to act as a conductive channel in the nanohybrid. Additionally, the intercalation of CNFs between the RGO sheets induced a 3D opened 
geometry in the electrode, which allowed facile ion and charge transfer. Consequently, high-performance capacitive properties were observed for these new 3D structures [40-43].
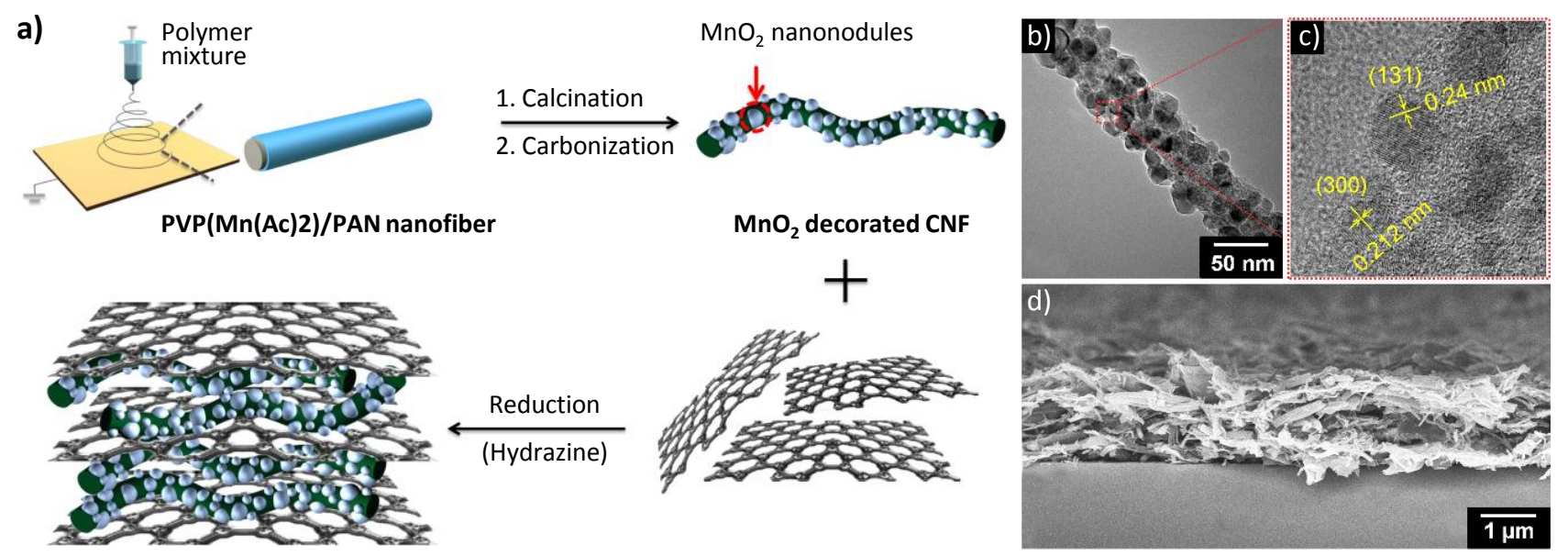

Figure 4. (a) Schematic of the fabrication of ternary hybrid nanostructures: MnO-decorated CNFs (MCNFs)/reduced graphene oxide (RGO) nanohybrids; (b) Typical transmission electron microscopy (TEM) image of MCNF; (c) High-resolution TEM image of an MCNF (lattice planes of $\gamma-\mathrm{MnO}_{2}$, such as (131) and (300), are marked); and (d) Cross-sectional scanning electron microscopy (SEM) image of MCNF/RGO nanohybrids (RGO 50 wt.\%) deposited on a silicon wafer. With permission from [39]; Copyright 2013, Wiley-VCH Verlag GmbH \& Co. KGaA.

CNT-bridged graphene 3D building blocks were synthesized via the coulombic interaction between positively charged CNTs grafted by cationic surfactants and negatively charged GO sheets (Figure 5) [44]. The CNTs were intercalated into the nanoporous graphene layers to build pillared 3D structures, which increased the accessible surface area and allowed fast ion diffusion. Because of this unique 3D porous structure, the electrodes showed remarkable electrochemical performance in ionic liquid electrolytes [45].

However, it is difficult to prepare electrodes by using uniform nanostructured CNTs on special substrates, especially those with porous surface structures. Cellulose is the most abundant and sustainable natural polymer. Cellulose nanofibrils (CeNFs) derived from cellulose have high aspect ratios, excellent mechanical properties, excellent flexibility, and superior hydrophilicity [46]. A recent work reported the fabrication of a unique CeNF/carbon nanohybrid aerogel electrode material, shown in Figure 6. The CeNF-based aerogel possessed a porous structure and an extremely high porosity (resulting in ultralow density and a high specific surface area), as well as excellent electrolyte-absorption properties. Furthermore, the hydrophilicity of the CeNFs in the aerogel improved the contact between the electrodes and electrolytes, and it provided diffusion channels for the electrolyte ions, thus enhancing the performance of the EDLCs.

Various polymer precursors have been used to make new types of carbon nanomaterials. The main characteristics of the resultant carbon nanomaterials depend on the polymer precursors. It is relatively easy to control the morphology and composition of polymers, which offers opportunities for producing carbon nanomaterials with controlled structures and properties [47,48]. Several researchers have fabricated electrode materials via heat treatment of $\mathrm{GO}$ /polymer hybrid precursors, such as 
GO/polypyrrole (PPy) nanowires, GO/PPy nanotubes, and GO/polyaniline (PANI). Heat treatment of the $\mathrm{GO} /$ polymer hybrids resulted in the formation of graphene-embedded all-carbon nanostructures. These carbonized nanohybrids exhibited good performance as EDLC electrode materials.

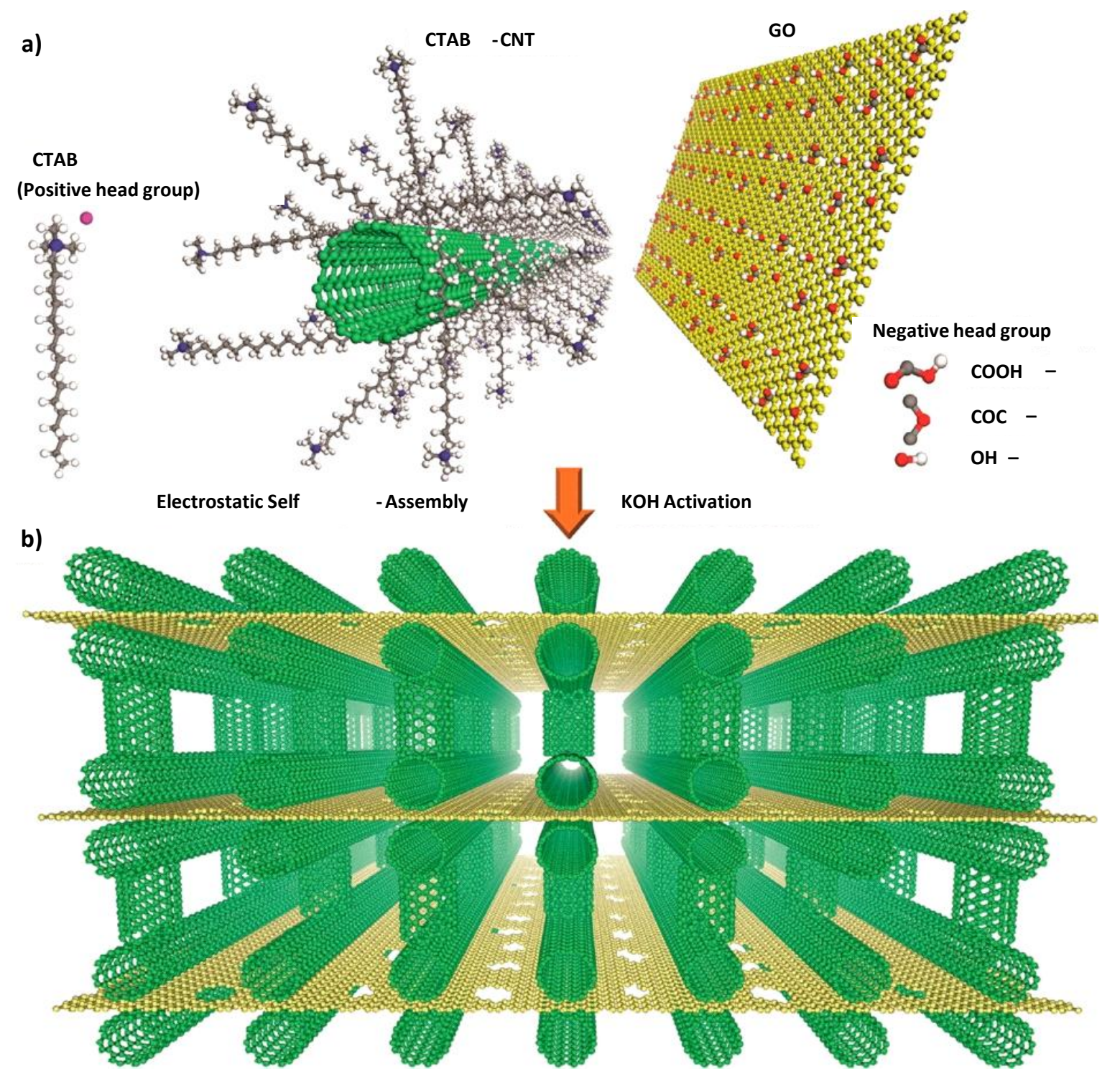

Figure 5. Schematic for fabricating the graphene/single-walled CNT hybrid nanostructure. (a) Cetyltrimethylammonium bromide (CTAB)-grafted CNTs are positively charged and the GO layers are negatively charged owing to their respective functional groups; (b) Schematic of the 3D CNT-bridged graphene block. $\mathrm{KOH}$ activation generates nanoscale pores in the graphene layers, which are expected to provide a simple means of ion diffusion. With permission from [44]; Copyright 2015, American Chemical Society. 
a)

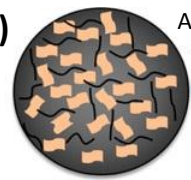

GO/CNT

dispersion

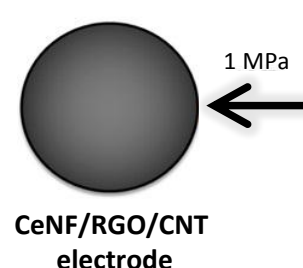

electrode

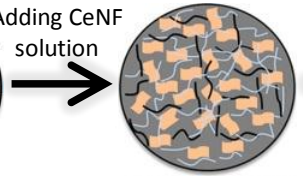

CeNF/GO/CNT

dispersion

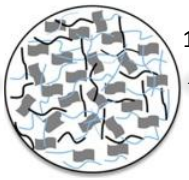

CeNF/RGO/CNT

aerogel

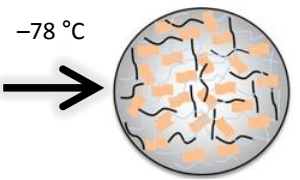

Frozen/CeNF/GO/CNT

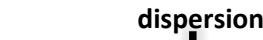

Freeze-drying

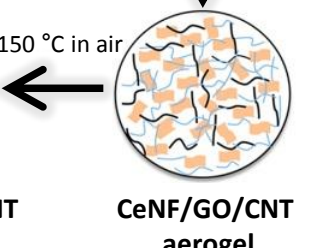

aerogel

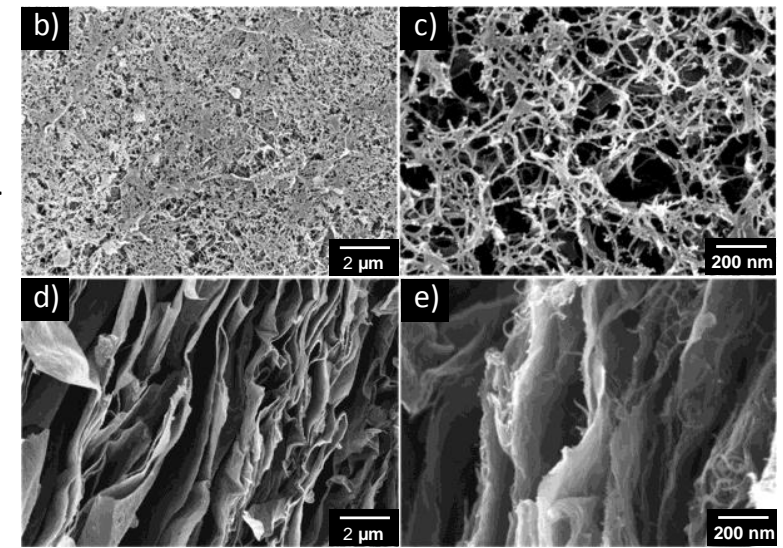

Figure 6. (a) Schematic of the fabrication process of a CeNF/RGO/CNT aerogel electrode. SEM images of compressed CeNF/RGO/CNT hybrid aerogel films, (b and $\mathbf{c}$ ) bottom surface of the aerogel film, and (d and e) cross section of the aerogel film. With permission from [46]; Copyright 2015, American Chemical Society.

\subsection{Summary}

EDLCs can be applied in the case of stationary and mobile systems requiring high power pulses. Moreover, owing to their low time constant, they can quickly harvest energy, such as during deceleration or braking of vehicles. Although EDLCs are able to provide higher power with a longer cycle life, they suffer from a relatively low energy density. Therefore, the current research is mainly concerned with the optimization of the existing electrode materials and the development of new materials to improve energy density. Many different carbon forms, such as CNTs, CNFs, activated carbon powders, and carbonized materials, can be used as active materials in EDLC electrodes [49,50]. Table 1 summarizes the EDLC electrode materials developed recently and their electrochemical performance.

Table 1. EDLC materials and electrochemical performance.

\begin{tabular}{|c|c|c|c|c|c|c|}
\hline Materials & $\begin{array}{l}\text { Electrode } \\
\text { System }^{(1,2)}\end{array}$ & Electrolyte & $\begin{array}{c}\text { Current Density } \\
\text { or Scan Rate }\end{array}$ & $\begin{array}{c}\text { Potential } \\
\text { Range } \\
\text { (V) }\end{array}$ & $\begin{array}{c}\text { Specific } \\
\text { Capacitance } \\
\left(\mathbf{F} \cdot \mathbf{g}^{-\mathbf{1}}\right)\end{array}$ & Ref. \\
\hline Carbon nanosheets & Two & (3) $\mathrm{EMIMBF}_{4}$ & $1-10 \mathrm{~A} \cdot \mathrm{g}^{-1}$ & 3.5 & $155-242$ & 6 \\
\hline Carbon nanosheets & Two & $\mathrm{PVA}-\mathrm{H}_{3} \mathrm{PO}_{4}$ gel & $0.25-1.3 \mathrm{~A} \cdot \mathrm{g}^{-1}$ & 0.8 & $4.9-29.2$ & 7 \\
\hline$N$-doped carbon nanosheets & Two & $1 \mathrm{M} \mathrm{NaOH}$ & $0.75-7 \mathrm{~A} \cdot \mathrm{g}^{-1}$ & 1.0 & $150-180$ & 8 \\
\hline Porous carbon nanowhiskers & Two & $6 \mathrm{M} \mathrm{KOH}$ & $0.5-30 \mathrm{~A} \cdot \mathrm{g}^{-1}$ & 1.0 & $125-210$ & 16 \\
\hline$N$-doped nanoporous carbon & Three & $6 \mathrm{M} \mathrm{KOH}$ & $0.5-40 \mathrm{~A} \cdot \mathrm{g}^{-1}$ & 1.0 & $90-240$ & 17 \\
\hline Nanofibers/mesoporous carbon & Three & $0.5 \mathrm{M} \mathrm{K}_{2} \mathrm{SO}_{4}$ & $0.5-6 \mathrm{~A} \cdot \mathrm{g}^{-1}$ & 0.8 & $72-99$ & 18 \\
\hline$N$-doped carbon nanospheres & Three & $6 \mathrm{M} \mathrm{KOH}$ & $0.5-40 \mathrm{~A} \cdot \mathrm{g}^{-1}$ & 1.0 & $62-194$ & 19 \\
\hline Nanoporous carbon & Two & (4) EMI-TFSI & $0.5-25 \mathrm{~A} \cdot \mathrm{g}^{-1}$ & 3.5 & $80-178$ & 21 \\
\hline$N$-doped nanoporous carbon & Three & $6 \mathrm{M} \mathrm{KOH}$ & $1-10 \mathrm{~A} \cdot \mathrm{g}^{-1}$ & 1.0 & $175-250$ & 22 \\
\hline Mesoporous carbon nanosheets & Two & $\begin{array}{c}\text { (5) } 1 \mathrm{M} \\
\mathrm{TEABF}_{4} / \mathrm{AN}\end{array}$ & $0.1-120 \mathrm{~A} \cdot \mathrm{g}^{-1}$ & 2.7 & $100-130$ & 24 \\
\hline GO-activate carbon & Two & $\mathrm{EMIMBF}_{4}$ & $1-10 \mathrm{~A} \cdot \mathrm{g}^{-1}$ & 3.5 & $110-135$ & 25 \\
\hline
\end{tabular}


Table 1. Cont.

\begin{tabular}{|c|c|c|c|c|c|c|}
\hline Materials & $\begin{array}{c}\text { Electrode } \\
\text { System }^{(1,2)}\end{array}$ & Electrolyte & $\begin{array}{l}\text { Current Density } \\
\text { or Scan Rate }\end{array}$ & $\begin{array}{c}\text { Potential } \\
\text { Range } \\
\text { (V) }\end{array}$ & $\begin{array}{c}\text { Specific } \\
\text { Capacitance } \\
\left(\mathbf{F} \cdot \mathbf{g}^{-1}\right)\end{array}$ & Ref. \\
\hline Porous carbon/CNTs & Two & $3 \mathrm{M} \mathrm{H}_{2} \mathrm{SO}_{4}$ & $0.1-50 \mathrm{~A} \cdot \mathrm{g}^{-1}$ & 0.9 & $125-237$ & 26 \\
\hline Porous CNFs & Two & EMI-TFSI & $5-100 \mathrm{mV} \cdot \mathrm{s}^{-1}$ & 2.0 & $65-150$ & 27 \\
\hline Porous CNTs & Three & $1 \mathrm{M} \mathrm{H}_{2} \mathrm{SO}_{4}$ & $1-10 \mathrm{~A} \cdot \mathrm{g}^{-1}$ & 0.7 & $454-710$ & 28 \\
\hline Nanoporous carbon foams & Two & $6 \mathrm{M} \mathrm{KOH}$ & $0.2-20 \mathrm{~A} \cdot \mathrm{g}^{-1}$ & 1.1 & $125-379$ & 29 \\
\hline Carbonization of carbon hydrates & Two & $5 \mathrm{M} \mathrm{KOH}$ & $1 \mathrm{~A} \cdot \mathrm{g}^{-1}$ & 0.8 & 140 & 32 \\
\hline Carbonized hollow nanocarbon & Two & $1 \mathrm{M} \mathrm{KOH}$ & $1-20 \mathrm{~A} \cdot \mathrm{g}^{-1}$ & 0.9 & $160-183$ & 35 \\
\hline Graphene-coated CNTs & Two & EMI-TFSI & $0.01-10 \mathrm{~A} \cdot \mathrm{g}^{-1}$ & 3.0 & $60-130$ & 36 \\
\hline Graphene/CNF & Three & $1 \mathrm{M} \mathrm{H}_{2} \mathrm{SO}_{4}$ & $0.2 \mathrm{~A} \cdot \mathrm{g}^{-1}$ & 1.5 & 174 & 39 \\
\hline 3D porous graphene-like carbon & Two & (6) $\mathrm{TEMABF}_{4} / \mathrm{PC}$ & $1-32 \mathrm{~A} \cdot \mathrm{g}^{-1}$ & 2.5 & $156-178$ & 40 \\
\hline Mesoporous graphene nanoballs & Three & $1 \mathrm{M} \mathrm{H}_{2} \mathrm{SO}_{4}$ & $5-100 \mathrm{mV} \cdot \mathrm{s}^{-1}$ & 0.8 & 206 & 41 \\
\hline Graphene/CNT composite fibers & Two & $0.5 \mathrm{M} \mathrm{H}_{2} \mathrm{SO}_{4}$ & $0.2-2 \mathrm{~A} \cdot \mathrm{g}^{-1}$ & 0.8 & $6-35$ & 42 \\
\hline$N$-doped 3D nanoporous carbon & Two & $0.5 \mathrm{M} \mathrm{Na}_{2} \mathrm{SO}_{4}$ & $0.5-20 \mathrm{~A} \cdot \mathrm{g}^{-1}$ & 1.0 & $226-304$ & 43 \\
\hline Graphene/CNT & Two & $\mathrm{EMIMBF}_{4}$ & $10 \mathrm{~A} \cdot \mathrm{g}^{-11}$ & 4.0 & 199 & 44 \\
\hline Graphene/carbon & Two & $\mathrm{EMIMBF}_{4}$ & $1-10 \mathrm{~A} \cdot \mathrm{g}^{-1}$ & 3.5 & $160-190$ & 45 \\
\hline RGO/CNT & Two & $\mathrm{PVA}-\mathrm{H}_{2} \mathrm{SO}_{4}$ gel & $0.5-4 \mathrm{~A} \cdot \mathrm{g}^{-1}$ & 1.0 & $180-252$ & 46 \\
\hline Carbonized PPy nanostructures & Three & $1 \mathrm{M} \mathrm{H}_{2} \mathrm{SO}_{4}$ & $5 \mathrm{mV} \cdot \mathrm{s}^{-1}$ & 0.9 & 264 & 47 \\
\hline Carbonized PPy-CNTs & Three & $1 \mathrm{M} \mathrm{KCL}$ & $5-100 \mathrm{mV} \cdot \mathrm{s}^{-1}$ & 1.5 & $40-140$ & 48 \\
\hline Halogen-containing nanoporous carbon & Three & $6 \mathrm{M} \mathrm{KOH}$ & $0.5-40 \mathrm{~A} \cdot \mathrm{g}^{-1}$ & 1.0 & $110-313$ & 49 \\
\hline Oxygen-rich nanoporous carbon & Two & $1 \mathrm{M} \mathrm{H}_{2} \mathrm{SO}_{4}$ & $0.5-10 \mathrm{~A} \cdot \mathrm{g}^{-1}$ & 1.0 & $210-297$ & 50 \\
\hline
\end{tabular}

(1) The "Two" indicates capacitor cells composed of two electrodes (anode/cathode), separator, and electrolyte, containing symmetric or asymmetric electrode configurations; ${ }^{(2)}$ The "Three" indicates electrode measuring systems composed of working electrode, counter electrode, and reference electrode in an electrolyte; (3) EMIMBF 4 : 1-ethyl-3-methylimidazolium tetrafluoroborate; (4) EMI-TFSI: 1-ethyl-3-methylimidazolium bis(trifluoromethylsulfonyl)imide; ${ }^{(5)} \mathrm{TEABF}_{4} / \mathrm{AN}$ : tetraethylammonium tetrafluoroborate/acetonitrile; ${ }^{(6)} \mathrm{TEMABF}_{4} / \mathrm{PC}$ : triethylmethylammonium tetrafluoroborate/propylene carbonate.

\section{Pseudocapacitive Materials}

Various methods of preparing pseudocapacitive materials have been recently described [51,52]. Pseudocapacitive materials show redox reactions during the charge/discharge process, thereby resulting in pseudocapacitors whose capacitance is better than that of EDLCs [53-55]. In most cases, however, faradaic redox reactions for pseudocapacitance are confined to the surfaces of the electrode materials. Thus, rational nanostructuring of pseudocapacitive materials for enlarging the effective surface area is essential to obtaining enhanced pseudocapacitance [56].

\subsection{Conducting Polymers}

Precise control over the size and morphology of conducting polymers on the nanoscale is essential to improving the performance of pseudocapacitors. However, the highly unstable nature of polymers on this scale has hindered the development of polymer nanoarchitectures [57]. Nevertheless, numerous efforts have been made to fabricate polymer nanomaterials with well-defined sizes and morphologies, and various types of conducting polymer nanostructures have been fabricated in a controlled manner [10,58]. 
Owing to their unique properties and small dimensions, conducting polymer nanostructures have wide technical applications [59,60]. For example, Figure 7 shows the SEM images of three PANI nanostructures synthesized with different shapes. PANI has been extensively used as an electrode-active material in electrochemical capacitors. The capacitances of these PANI nanostructures were determined via charge/discharge cycling. For the same range of potentials, the discharging time increased in the order of nanospheres < nanorods < nanofibers, indicating that the nanofiber electrode has the highest specific discharge capacitance [61]. In other words, the capacitance of PANI nanostructures depends on their aspect ratio. The nanofibers also had faster electrode kinetics by virtue of the higher oxidation level and crystallinity. Lastly, interparticle resistance varied as a function of the aspect ratio of the nanostructures, which has been identified as one of the significant factors affecting the electrode performance. Several papers have similarly described the morphology effect of nanoparticles on the performance of pseudocapacitors [10,58,61]. As a result, judicious control of the morphology of nanostructures for electrode materials offers many possibilities of tailoring the performance of electrochemical capacitors.
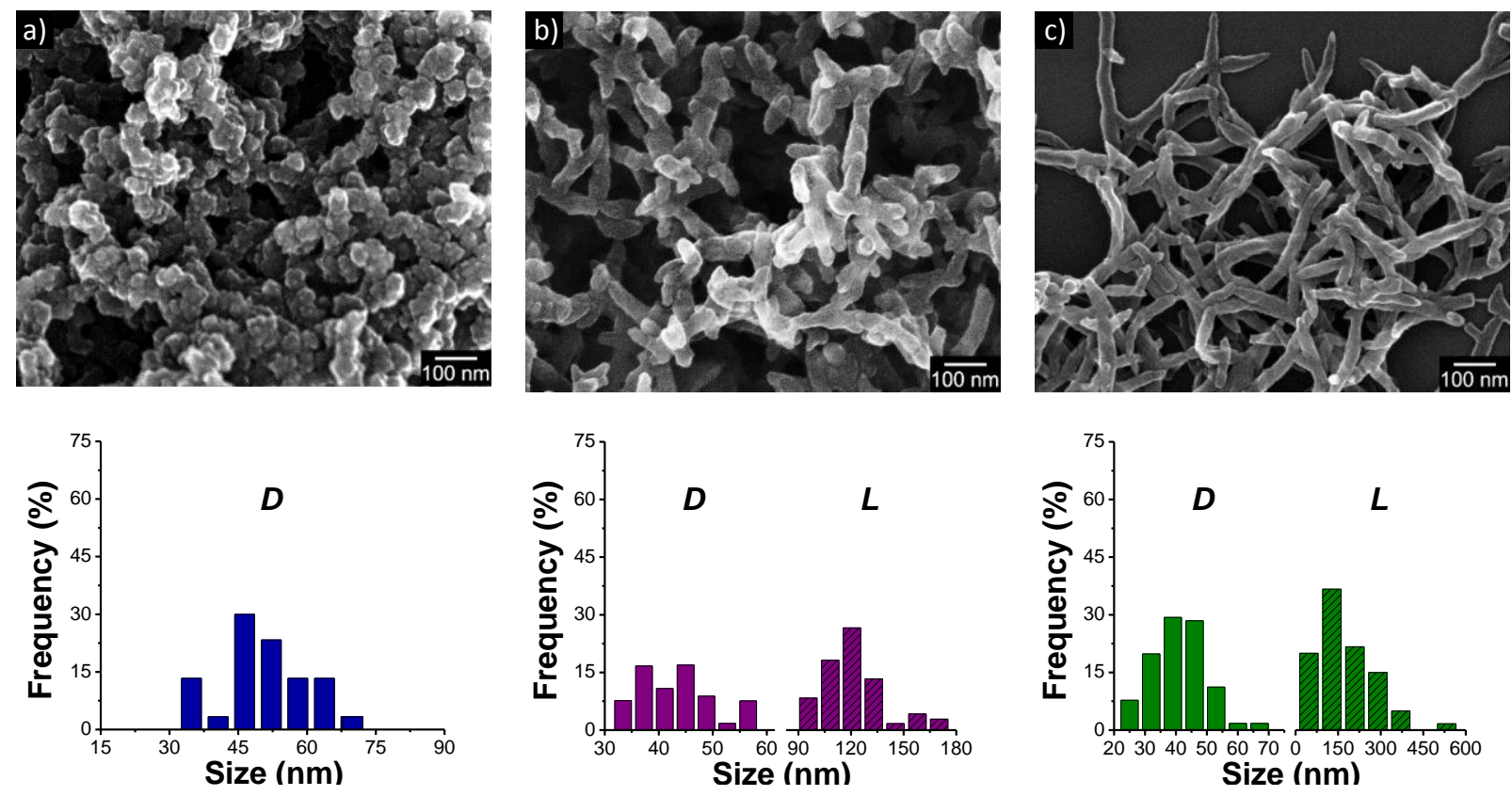

Figure 7. SEM images of polyaniline (PANI) nanostructures with different aspect ratios synthesized under the same stirring condition (200 rpm) and histograms showing their size distribution (D, diameter; L, length): (a) Nanospheres; (b) Nanorods; and (c) Nanofibers. With permission from [61]; Copyright 2012, American Chemical Society.

Precise control of the nanostructure morphology is crucial to realizing a variety of next-generation technologies. Poly(3,4-ethylenedioxythiophene) (PEDOT) and multidimensional PPy nanotubes are only two examples of these promising nanostructures [62]. The surface of the former was decorated with substructures such as nanonodules and nanorods and the latter were fabricated as chemiresistors on a sacrificial nanofiber template by vapor deposition polymerization (VDP) [63]. These unique multidimensional nanostructures have enhanced surface-to-volume ratios, and their unique morphology and anisotropic geometry results in a high surface area and excellent charge-transport properties. These 
advantages are expected to induce a synergetic effect that enhances device performance, particularly in pseudocapacitors.

Electrospinning is a simple and scalable technique that can create continuous and aligned polymer nanofibers and microfibers under a large electric field. Electrospun nanofibers are composed of various polymer melts and solutions, which can serve as templates that direct the formation of conducting polymer nanofibers and nanotubes. In a recent study, ultrathin poly(methyl methacrylate) (PMMA) nanofibers with an average diameter of $60 \mathrm{~nm}$ were obtained through electrospinning for use as a template (Figure $8 b$ ); these nanofibers were then immersed in a ferric chloride solution in order to adsorb ferric ions onto the PMMA nanofibers (Figure 8c) [64]. Subsequent coating of PEDOT onto the PMMA nanofibers via VDP at controlled temperatures and pressures yielded core-shell-structured nanofibers (Figure 8d,f,h). Unique surface substructures such as nanonodules and nanorods were grown on the nanofibers by adjusting the major kinetic factors. Moreover, the PMMA was removed by selective solvent etching, which resulted in nanotubular structures (Figure 8e,g,i). These multidimensional nanofibers and nanotubes with surface substructures offer significant advantages when used as pseudocapacitors.

VDP has attracted significant attention owing to its simplicity and controllability as compared to other techniques used to obtain nanostructured conducting polymers [65]. As a conjugated polymer, PPy shows practical potential for a diverse and promising range of future technologies. Free-standing, flexible, and large-area PPy/cellulose (PPCL) papers were readily prepared using VDP (Figure 9), and PPy coatings on cellulose microfibers were influenced by the properties of co-vapors introduced together with pyrrole during polymerization [66].

It is known that PPy stores electrical charges through a pseudocapacitive charge storage mechanism mediated by a redox reaction. Pseudocapacitance stems from reversible surface or near-surface reactions for charge storage. As a result, use of co-vapors in VDP has offered the possibility of tuning the physical properties of the deposited polymers, as well as the performance of the polymer-based electrochemical capacitors.

Conducting polymers can also be coated on metal nanoparticles to improve the electrochemical performance. Uniform coating of the metal nanoparticles with conducting polymer layers prevents interparticle aggregation and imparts unprecedented electrical, optical, and chemical properties to the nanoparticles.

Ag-PPy core-shell nanoparticles were obtained in the form of a stable colloidal suspension through a simple one-pot synthesis [67]. Briefly, the silver nanoseed surfaces became the active sites for oxidation of the surrounding pyrrole monomers and PPy short chains, thereby resulting in the formation of a PPy shell (Figure 10). These bottom-up approaches offer an efficient and simple route for the fabrication of nanostructured metal/conducting polymer complexes. 


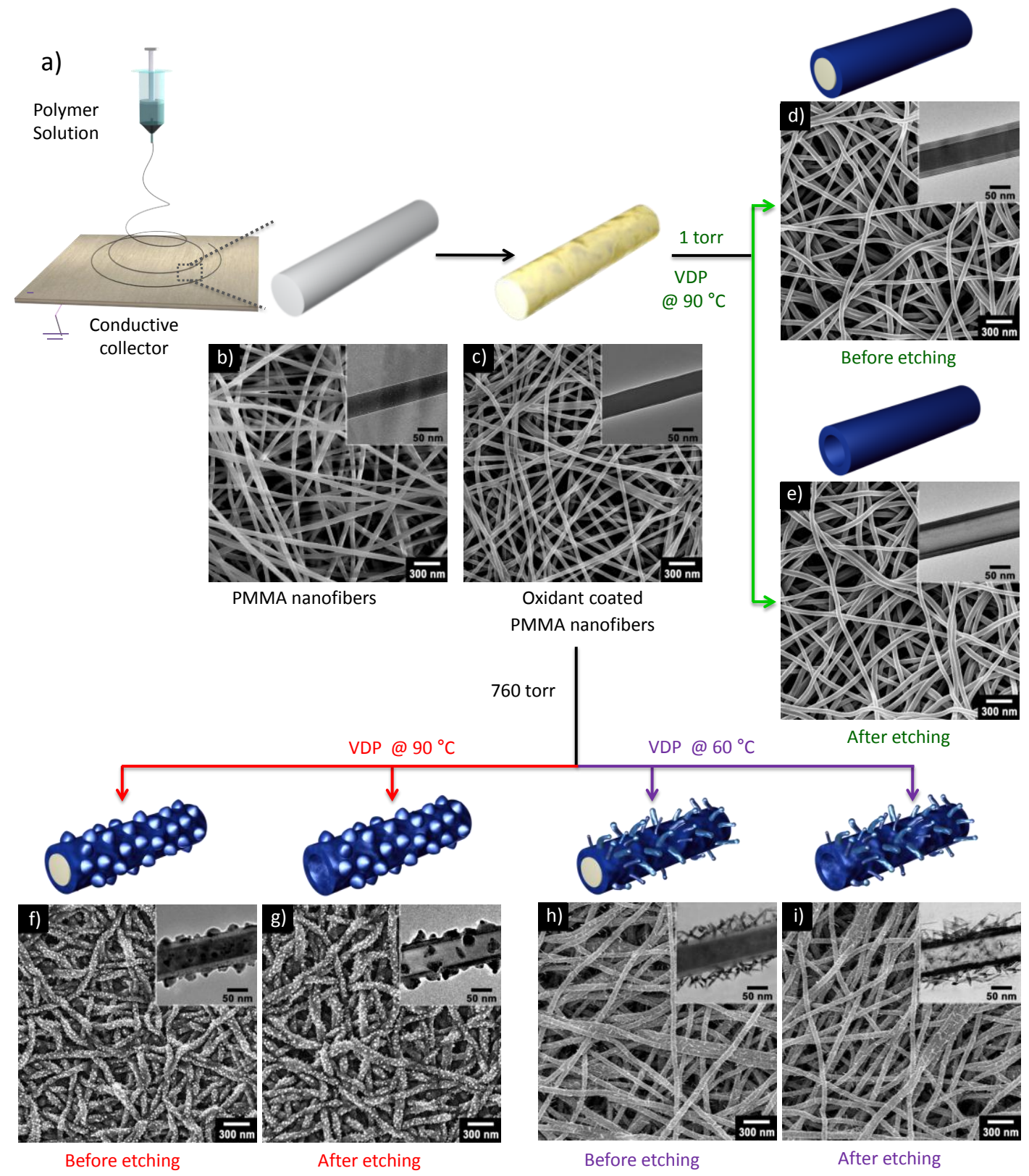

Figure 8. Multidimensional poly(3,4-ethylenedioxythiophene) (PEDOT) nanostructures with unique surface substructures. (a) Schematic of the synthetic routes for fabricating multidimensional PEDOT nanostructures; (b-i) The poly(methyl methacrylate) (PMMA) nanofibers serve as a template and substrate for the growth of PEDOT under different synthetic conditions (temperature and pressure). The morphologies of the resulting nanomaterials were characterized by SEM and TEM (right top inset images): PMMA nanofibers (b) before and (c) after ferric ion adsorption; PMMA/PEDOT nanofibers with a smooth layer surface (d) before and (e) after core etching; PMMA/PEDOT nanofibers with nanorod surface (f) before and (g) after core etching; PMMA/ PEDOT nanofibers with NN surface (h) before and (i) after core etching. With permission from [64]; Copyright 2012, American Chemical Society. 

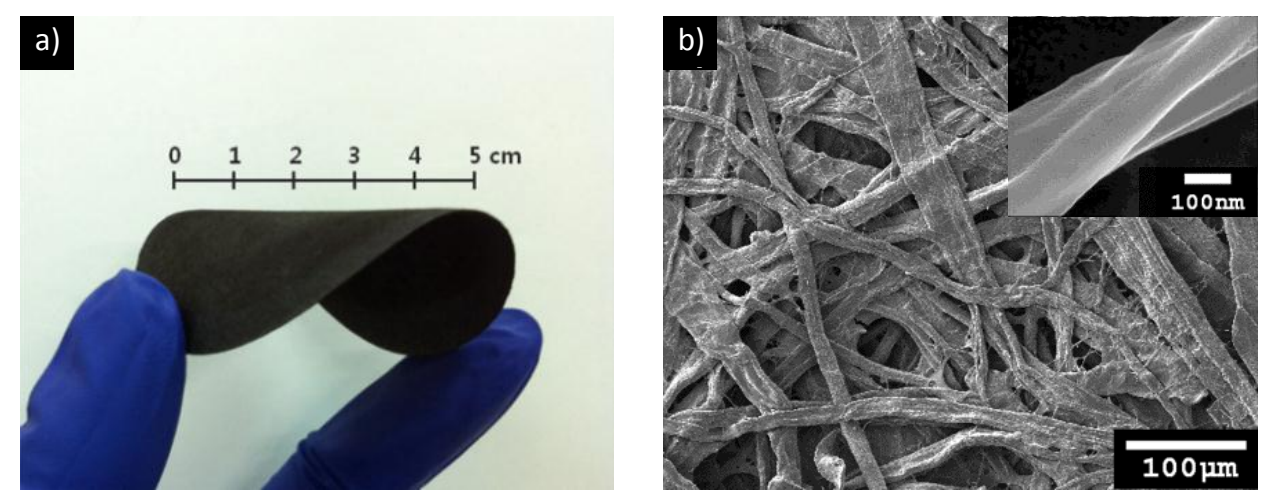

Figure 9. (a) Photograph showing the flexibility of a large-area, free-standing PPy/cellulose (PPCL) paper; (b) SEM images of a PPCL paper (inset: high-magnification image). With permission from [65]; Copyright 2014, The Royal Society of Chemistry.

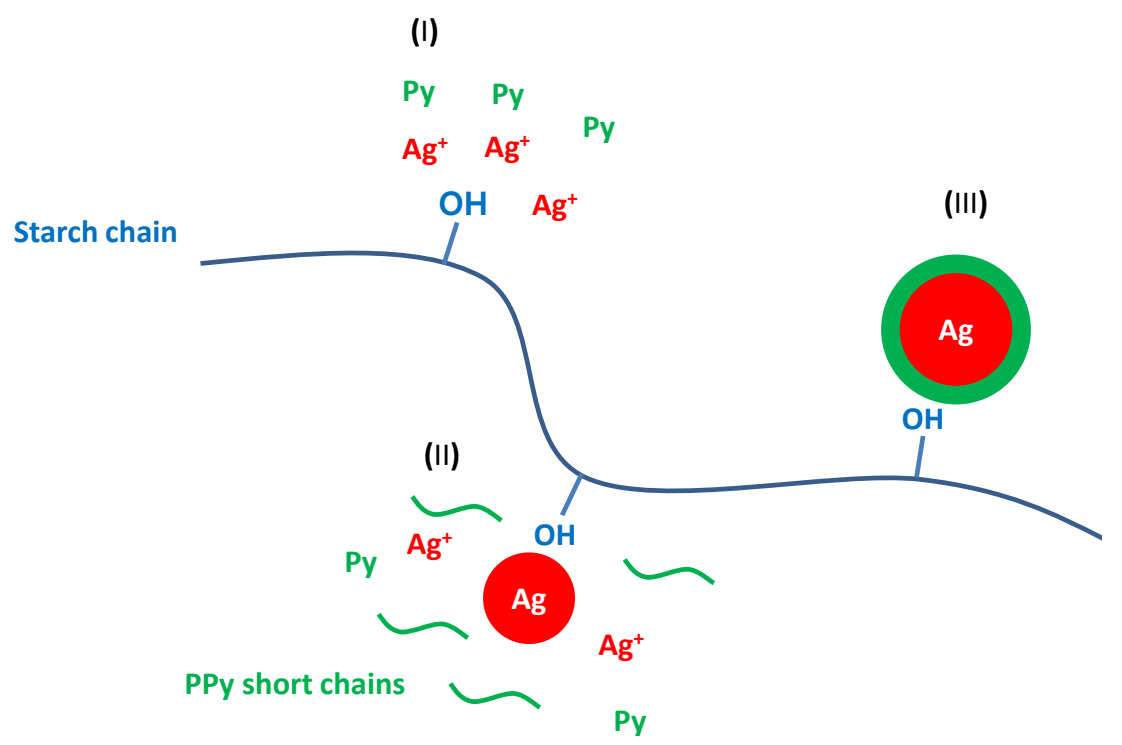

Figure 10. Schematic of the formation mechanism of Ag-PPy nanoparticles: the reaction process consisted of three stages (I, II, and III). With permission from [67]; Copyright 2012, American Chemical Society.

\subsection{Metal Oxides}

Metal oxides are attractive pseudocapacitive electrode materials because of their easy processing [5]. Ruthenium oxides and manganese oxides have been widely studied for electrochemical capacitor applications $[68,69]$. However, the high cost of ruthenium oxides excludes them from wide practical application. Additionally, manganese oxides have several different crystalline structures, such as $\alpha-, \beta-, \gamma-$, $\delta$-, and $\xi-\mathrm{MnO}_{2}$, and unfortunately their capacitances highly depend on the crystalline structure [70-74]. Therefore, recent research trends have focused on exploring other transition metal oxides. For example, a binary transition metal sulfide, $\mathrm{NiCo}_{2} \mathrm{~S}_{4}$, with a hollow hexagonal nanoplate structure was successfully prepared through a hydrothermal route with the aid of a sacrificial template. The $\mathrm{NiCo}_{2} \mathrm{~S}_{4}$ gave a maximum specific capacitance of $437 \mathrm{~F} \cdot \mathrm{g}^{-1}$ in a $\mathrm{KOH}$ electrolyte at a current density of $1 \mathrm{~A} \cdot \mathrm{g}^{-1}$ [75]. However, poor conductivity of metal oxides poses a serious problem to the efficient use of these oxides in electrochemical capacitors. A nanocomposite composed of a metal oxide and a conductive material 
can be designed in order to overcome this drawback [66,76,77]. For example, it was found that CoO-based PPy nanowire electrodes had very high capacitance and good rate capability [78]. Using nanoporous silica as a template enables the fabrication of pseudocapacitor electrodes, which have narrow particle size and pore-size distributions, large surface area, and large pore volume. As compared to normal PPy, enhanced conductivity and surface area were observed due to the synergistic effect of the nanohybrid structures. As a result, the CoO/PPy nanowires showed excellent pseudocapacitance behavior [79].

Extensive research has also focused on maximizing the specific surface area of metal oxides through hierarchical structuring of the composite [80-83]. As an example, Ding and Yang reported the preparation of a $1 \mathrm{D}$ hierarchical nanostructure of $\mathrm{NiCo}_{2} \mathrm{O}_{4}$ nanosheets @ halloysite nanotubes through simple co-precipitation followed by thermal annealing (Figure 11) [84]. The hierarchical nanostructure had an excellent specific capacitance of $1728 \mathrm{~F} \cdot \mathrm{g}^{-1}$ even after 8600 cycles at a current density of $10 \mathrm{~A} \cdot \mathrm{g}^{-1}$.

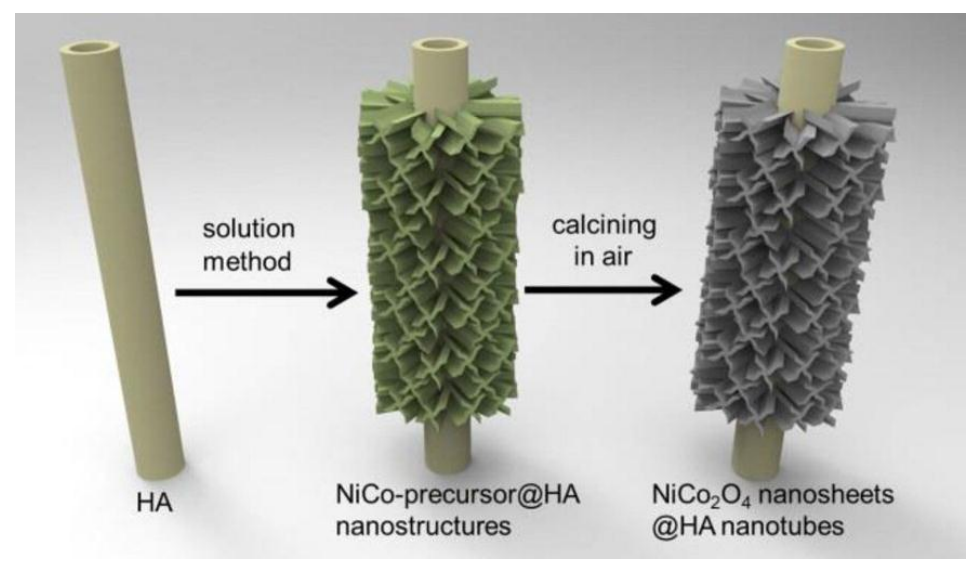

Figure 11. Schematic of the synthetic procedure of $\mathrm{NiCo}_{2} \mathrm{O}_{4}$ nanosheets@halloysite nanotube hybrid nanostructures. With permission from [84]; Copyright 2012, American Chemical Society.

\subsection{Summary}

In recent years, various methods for fabricating pseudocapacitive materials have been reported. Table 2 summarizes the pseudocapacitive electrode materials and their electrochemical performance. Owing to the redox reaction-mediated charge storage, pseudocapacitive materials have higher energy density than their EDLC counterparts. The enhanced surface area and redox activity was achieved primarily by controlling the morphology and by combining materials. However, pseudocapacitive materials, especially conducting polymers, undergo severe volumetric changes during charge/discharge processes, often leading to structural deterioration and rapid decay of the capacitance. Long-term cycling stability is, therefore, a barrier to the wide use of pseudocapacitors in practical applications. 
Table 2. Pseudocapacitor materials and electrochemical performance.

\begin{tabular}{|c|c|c|c|c|c|c|}
\hline Materials & $\begin{array}{l}\text { Electrode } \\
\text { System }^{(1,2)}\end{array}$ & Electrolyte & $\begin{array}{c}\text { Current Density } \\
\text { or Scan Rate }\end{array}$ & $\begin{array}{c}\text { Potential } \\
\text { Range } \\
\text { (V) }\end{array}$ & $\begin{array}{c}\text { Specific } \\
\text { Capacitance } \\
\left(\mathbf{F} \cdot \mathbf{g}^{-1}\right) \\
\end{array}$ & Ref. \\
\hline $\mathrm{CoCl}_{2}$ nanostructures & Three & $2 \mathrm{M} \mathrm{KOH}$ & $1 \mathrm{~A} \cdot \mathrm{g}^{-1}$ & 0.45 & 1962 & 9 \\
\hline PANI nanotubes & Two & $1 \mathrm{M} \mathrm{H}_{2} \mathrm{SO}_{4}$ & $1-30 \mathrm{~A} \cdot \mathrm{g}^{-1}$ & 0.5 & $477-896$ & 10 \\
\hline PPy-clay core-shell nanoarrays & Three & $1 \mathrm{M} \mathrm{KOH}$ & $1-20 \mathrm{~A} \cdot \mathrm{g}^{-1}$ & 1.2 & $1750-2342$ & 11 \\
\hline Polythiophene nanostructures & Two & $0.5 \mathrm{M} \mathrm{TEABF}_{4}$ & $40-100 \mathrm{mV} \cdot \mathrm{s}^{-1}$ & 4.0 & $75-250$ & 12 \\
\hline $\mathrm{NiO}$ nanoblocks & Three & $1 \mathrm{M} \mathrm{KOH}$ & $1.11-111 \mathrm{~A} \cdot \mathrm{g}^{-1}$ & 0.6 & $680-1336$ & 51 \\
\hline PPy-sepiolite nanocomposites & Three & $1 \mathrm{M} \mathrm{KCl}$ & $3 \mathrm{~mA} \cdot \mathrm{cm}^{-2}$ & 1.0 & 165 & 52 \\
\hline $\mathrm{ZnCo}_{2} \mathrm{O}_{4}$ nanorods/Ni foams & Two & PVA-KOH gel & $1-20 \mathrm{~A} \cdot \mathrm{g}^{-1}$ & 1.0 & $1015-1400$ & 53 \\
\hline $\mathrm{NiCo}_{2}(\mathrm{OH})_{6}$ nanotubes & Two & 1.9 M KCL 0.1M KOH & $10-100 \mathrm{~A} \cdot \mathrm{g}^{-1}$ & 0.5 & $169-200$ & 54 \\
\hline $3 \mathrm{D} \mathrm{Co}_{3} \mathrm{O}_{4}$ nanonetworks & Three & $6 \mathrm{M} \mathrm{KOH}$ & $2-100 \mathrm{mV} \cdot \mathrm{s}^{-1}$ & 1.5 & $546-1049$ & 55 \\
\hline $\mathrm{Ni}_{2}\left(\mathrm{CO}_{3}\right)(\mathrm{OH})_{2}$ nanosheets & Three & $3 \mathrm{M} \mathrm{KOH}$ & $0.5-10 \mathrm{~A} \cdot \mathrm{g}^{-1}$ & 0.4 & $612-1178$ & 56 \\
\hline $\begin{array}{c}\text { PPy-PANI double-wall } \\
\text { nanotubes }\end{array}$ & Three & $1 \mathrm{M} \mathrm{H}_{2} \mathrm{SO}_{4}$ & $5-250 \mathrm{mV} \cdot \mathrm{s}^{-1}$ & 0.6 & $366-693$ & 58 \\
\hline PANI nanofibers & Three & $1 \mathrm{M} \mathrm{H}_{2} \mathrm{SO}_{4}$ & $0.1-10 \mathrm{~A} \cdot \mathrm{g}^{-1}$ & 0.8 & 20-192 & 61 \\
\hline PPy nanofibrils & Three & $1 \mathrm{M} \mathrm{H}_{2} \mathrm{SO}_{4}$ & $0.1 \mathrm{~A} \cdot \mathrm{g}^{-1}$ & 0.7 & 280 & 62 \\
\hline Hollow $\mathrm{NiCo}_{2} \mathrm{~S}_{4}$ nanoplates & Three & $3 \mathrm{M} \mathrm{KOH}$ & $1-20 \mathrm{~A} \cdot \mathrm{g}^{-1}$ & 0.5 & $231-437$ & 63 \\
\hline$\alpha-\mathrm{Fe}_{2} \mathrm{O}_{3} / \mathrm{MnO}_{2}$ nanowires & Three & $0.7 \mathrm{M} \mathrm{H}_{3} \mathrm{BO}_{3}$ & $1-50 \mathrm{~A} \cdot \mathrm{g}^{-1}$ & 0.6 & $480-838$ & 70 \\
\hline 2D TiS 2 nanocrystals & Three & $1 \mathrm{M} \mathrm{LiClO}_{4}$ & $0.5-10 \mathrm{~A} \cdot \mathrm{g}^{-1}$ & 1.2 & $320-470$ & 71 \\
\hline CoAl/PEDOT nanoarrays & Three & $6 \mathrm{M} \mathrm{KOH}$ & $1-40 \mathrm{~A} \cdot \mathrm{g}^{-1}$ & 0.6 & $424-672$ & 76 \\
\hline $\begin{array}{l}\mathrm{Au}-\mathrm{MnO}_{2} \text { core-shell } \\
\text { nanomesh }\end{array}$ & Two & $\mathrm{PVA}^{-\mathrm{LiClO}_{4} \text { gel }}$ & $0.56 \mathrm{~A} \cdot \mathrm{g}^{-1}$ & 2.0 & 524 & 77 \\
\hline $\mathrm{CoO} / \mathrm{PPy}$ nanowires & Two & $3 \mathrm{M} \mathrm{NaOH}$ & $1-50 \mathrm{~mA} \cdot \mathrm{cm}^{-2}$ & 1.6 & $647-2223$ & 78 \\
\hline $\mathrm{V}_{2} \mathrm{O}_{5}$-PPy nanofibers & Two & PVA-LiCl gel & $4.5 \mathrm{~mA} \cdot \mathrm{cm}^{-2}$ & 2.0 & 412 & 79 \\
\hline $\mathrm{CuO}$ nanowires & Three & $2 \mathrm{M} \mathrm{KOH}$ & $1-5 \mathrm{~A} \cdot \mathrm{g}^{-1}$ & 0.45 & $102-118$ & 80 \\
\hline Nanoporous $\mathrm{Ni}(\mathrm{OH})_{2}$ films & Two & $6 \mathrm{M} \mathrm{KOH}$ & $0.9-50 \mathrm{~A} \cdot \mathrm{g}^{-1}$ & 1.6 & 20-192 & 81 \\
\hline$\beta-\mathrm{Co}(\mathrm{OH})_{2}$ nanosheets & Two & $2 \mathrm{M} \mathrm{KOH}$ & $1-25 \mathrm{~A} \cdot \mathrm{g}^{-1}$ & 0.5 & $1530-2080$ & 82 \\
\hline $\mathrm{Co}_{3} \mathrm{O}_{4}$ nanostructures & Two & $2 \mathrm{M} \mathrm{KOH}$ & $0.5-2.5 \mathrm{~A} \cdot \mathrm{g}^{-1}$ & 0.8 & $150-476$ & 83 \\
\hline $\mathrm{NiCO}_{2} \mathrm{O}_{4}$ nanosheets & Three & $2 \mathrm{M} \mathrm{KOH}$ & $6-30 \mathrm{~A} \cdot \mathrm{g}^{-1}$ & 0.5 & $1500-1886$ & 84 \\
\hline
\end{tabular}

(1) The "Two" indicates capacitor cells composed of two electrodes (anode/cathode), separator, and electrolyte, containing symmetric or asymmetric electrode configurations. ${ }^{(2)}$ The "Three" indicates electrode measuring systems composed of working electrode, counter electrode, and reference electrode in an electrolyte.

\section{Hybrid Capacitive Materials}

Carbon materials have excellent electrical properties such as conductivity, power density, and long-term cycling stability; however, overcoming their low energy density has been the subject of intensive research $[85,86]$. The specific capacitance of carbon materials can be improved by mixing them with pseudocapacitive active materials [87]. The pseudocapacitance of electronically conducting polymers stems from rapid and reversible oxidation and reduction processes. EDLCs composed of pseudocapacitive-based nanostructures can store charge on the electrode surface both through a double layer and via a redox reaction. The low cycling stability of pseudocapacitive materials can be overcome through the use of carbon materials. Several active materials, including conducting polymers PPy, PANI, or metal oxides, have been directly grown on carbon owing to the properties imparted by these carbon-based 
materials [88-90]. These properties could be combined with those of the transition metal oxides and polymers, leading to the development of a new brand of electrochemical capacitors.

\subsection{Coupling EDLC and Pseudocapacitive Materials}

Carbon-coated conducting polymers have, in general, excellent cycling stability, as well as high energy and power density [91]. More importantly, carbon materials enhance the corresponding cycling stability and prevent the structural breakdown of pseudocapacitive conducting polymers [92]. The energy density is also improved with the aid of the pseudocapacitance stemming from the conducting polymers.

For example, exceptional capacitance retention of $95 \%$ and $85 \%$ after 10,000 cycles were recently reported for carbon-coated PANI and PPy [93]. These retention rates are the best values ever obtained for polymer-based pseudocapacitive electrodes in an aqueous electrolyte. These results show that the carbon material was very effective in maintaining the structures of the PANI and PPy nanowire electrodes during charge/discharge cycling, thereby resulting in excellent capacitance retention rates. The carbon-coated PANI and PPy electrodes exhibited similar pseudocapacitive behavior and specific capacitance as compared to bare polymer samples. Furthermore, the excellent electrochemical performance of the polymer electrodes was maintained, even with improvement in cycling stability [94].

a)

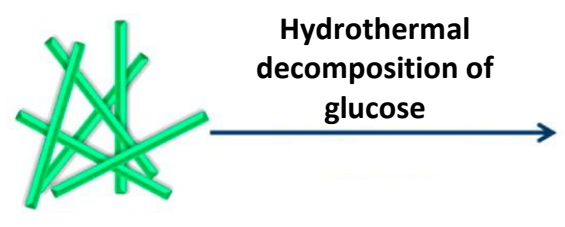

PPy or PANI
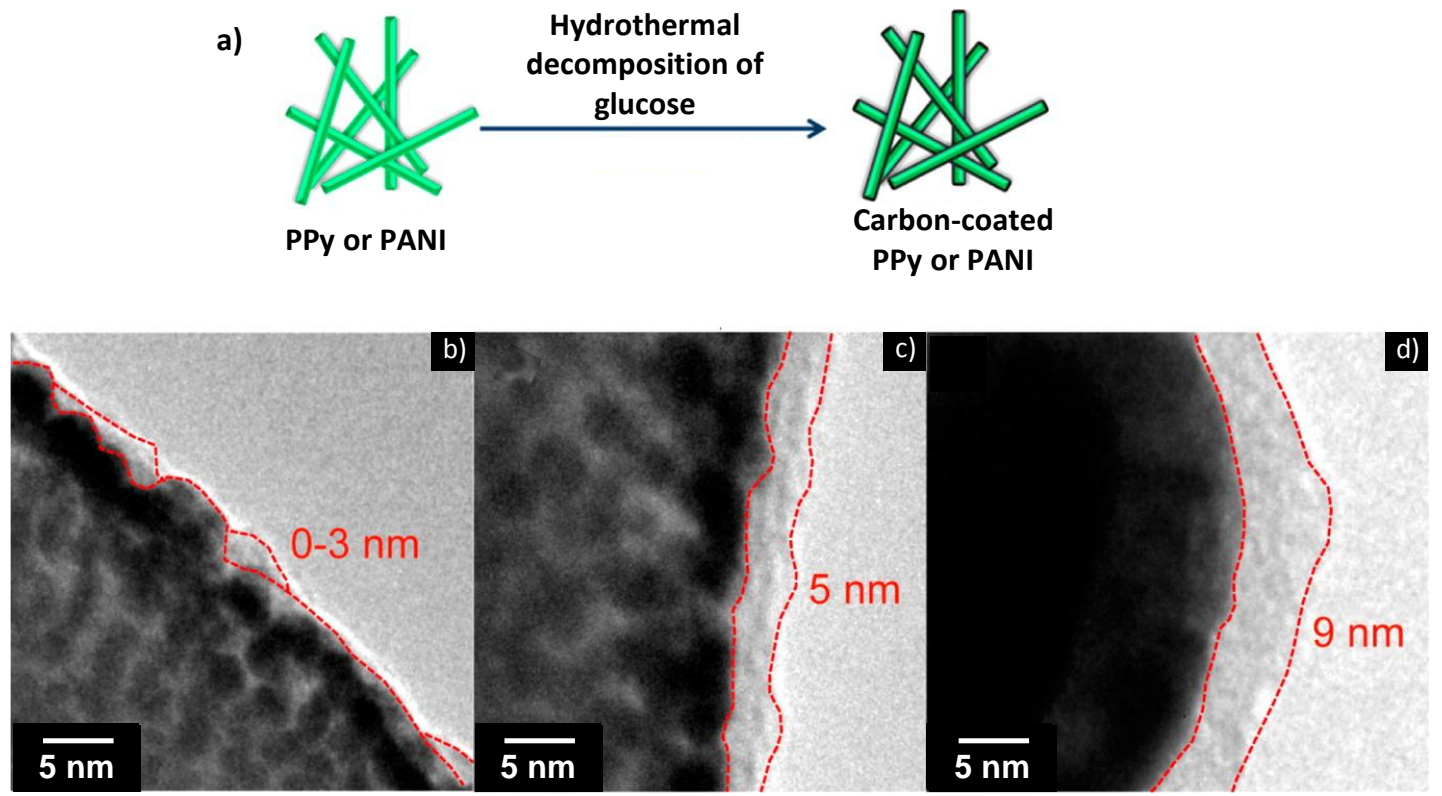

Figure 12. (a) Schematic of the carbonaceous coating procedure using glucose as the carbon precursor. (b-d) TEM images of carbon-coated PPy samples with different carbonaceous shell thicknesses, which was controlled via the reaction time for the hydrothermal deposition of glucose: (b) 1, (c) 2, and (d) $3 \mathrm{~h}$. With permission from [93]; Copyright 2014, American Chemical Society.

Nickel- and manganese-based oxides/hydroxides have high theoretical specific capacitance. They are also inexpensive, naturally abundant, and environmentally friendly. Metal-oxide and graphene-oxide hybrid capacitors have many outstanding properties. Nickel hydroxide-manganese dioxide-RGO $\left[\mathrm{Ni}(\mathrm{OH})_{2}-\mathrm{MnO}_{2}-\mathrm{RGO}\right]$ ternary hybrid spherical powders were fabricated as electrode materials [95]. These materials have a highly porous nanostructure, relatively high specific surface area, and well-defined 
spherical morphology. In addition, the synergetic effect of $\mathrm{Ni}(\mathrm{OH})_{2}, \mathrm{MnO}_{2}$, and $\mathrm{RGO}$ resulted in significantly enhanced specific capacitance of the electrode materials composed of these novel $\mathrm{Ni}(\mathrm{OH})_{2}-\mathrm{MnO}_{2}-\mathrm{RGO}$ ternary hybrid spheres

\subsection{Asymmetric Hybrid Capacitors}

The development of asymmetric capacitors for improving the energy and power density of electrochemical capacitors has been extensively studied. Combining the advantages of long-term cycling, a fast and reversible nonfaradaic negative electrode (-), and a high-capacitive positive faradaic electrode (+), asymmetric capacitors should fulfill the requirements of high energy and power density [96-98].

To fabricate asymmetric capacitors, $\mathrm{Mn}-\mathrm{Ni}-\mathrm{Co}$ ternary oxide (MNCO) nanowires were synthesized by a simple hydrothermal method [99]. The exceptional performance of these capacitors was a result of their nanowire architecture, which provided a large reaction surface area and fast ion and electron transfer. An asymmetric hybrid capacitor with high energy density was assembled successfully by employing an MNCO nanowire (+)//carbon black (-) cell. Figure 13 shows an image of an asymmetric hybrid capacitor and the improved electrochemical performance of an asymmetric cell.

a)

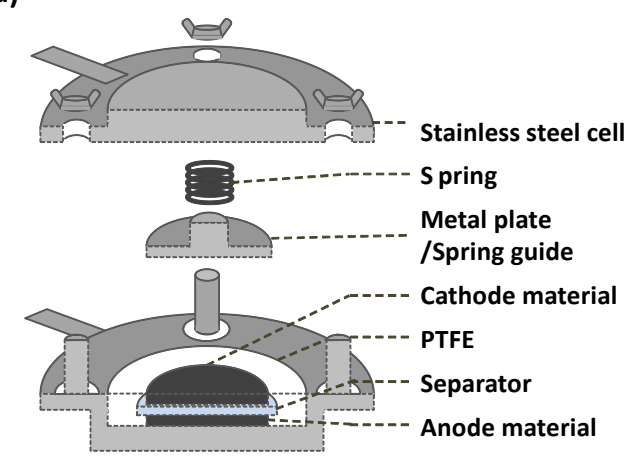

b)

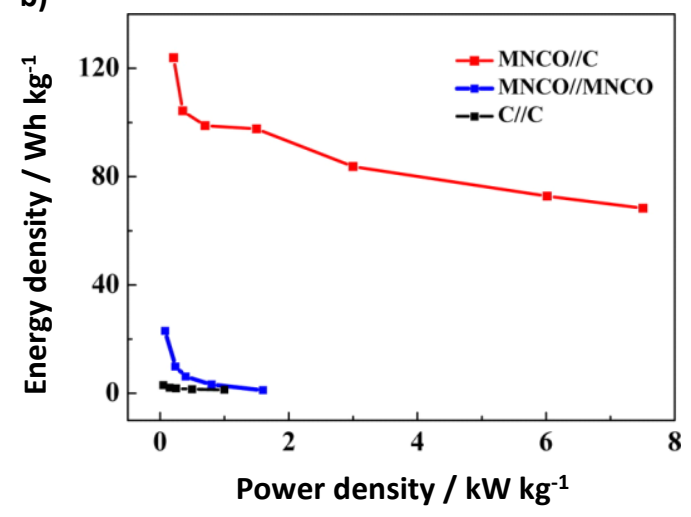

Figure 13. (a) Schematic of a representative asymmetric cell. With permission from [100]; Copyright 2014, The Royal Society of Chemistry. (b) Ragone plots of the as-fabricated asymmetric $\mathrm{MNCO} / /$ carbon black, symmetric $\mathrm{MNCO} / \mathrm{MNCO}$, and symmetric carbon black//carbon black electrochemical capacitors. With permission from [99]; Copyright 2012, American Chemical Society.

In another study, $\mathrm{MnO}_{2}-\mathrm{PEDOT}$ nanotubes (mPNTs) were tested in asymmetric hybrid cell configurations, without using binders or conductive fillers, where RGO-CNFs were employed as an electric double-layer electrode material [100]. Surface redox reactions between the transition metal oxides and PEDOT resulted in the desired pseudocapacitance. Moreover, PEDOT has a nano-scale hierarchical structure, which provides a large effective surface area and efficient charge transfer. CNFs were intercalated between the RGO sheets to prevent the restacking of the sheets and to increase the nonfaradaic charge storage. The asymmetric $\mathrm{MnO}_{2}-\mathrm{mPNTs}(+) / / \mathrm{RGO}-\mathrm{CNFs}(-)$ cell also exhibited superior specific capacitance, cycling stability, and coulombic efficiency as compared to symmetric cells comprising the $\mathrm{MnO}_{2}-\mathrm{mPNT} / \mathrm{RGO}-\mathrm{CNF}$ combination. Furthermore, the capacitive performance of the 
asymmetric $\mathrm{MnO}_{2}-\mathrm{mPNT}(+) / / \mathrm{RGO}-\mathrm{CNF}(-)$ cells were examined in terms of the weight ratio of the positive/negative electrode materials. As Figure 14 shows, the capacitance of the asymmetric $\mathrm{MnO}_{2}-\mathrm{mPNT} / \mathrm{RGO}-\mathrm{CNF}$ cell decreased and the coulombic efficiency increased with increasing weight of the RGO-CNFs. The capacitive performance of the asymmetric cells was, therefore, highly dependent on the weight ratio of the electrode $[101,102]$.

a)

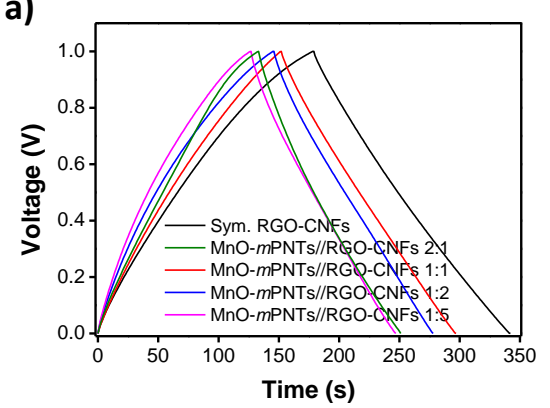

b)

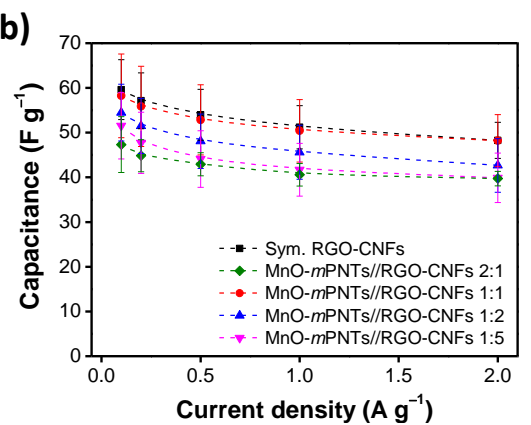

c)

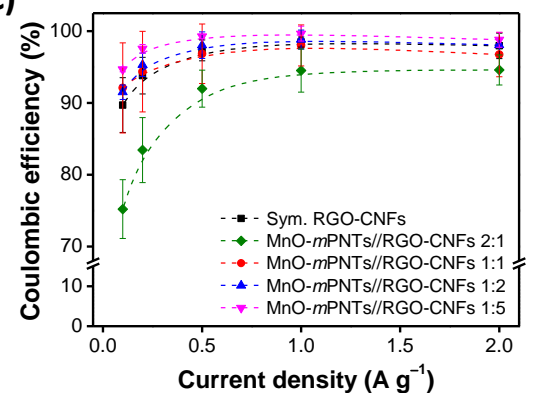

Figure 14. Effect of electrode weight: (a) Representative charge/discharge curves measured at $0.1 \mathrm{~A} \cdot \mathrm{g}^{-1}$; (b) Specific capacitances; and (c) Coulombic efficiencies measured at different current densities. With permission from [100]; Copyright 2014, The Royal Society of Chemistry.

\subsection{D Nanostructured Graphene-Based Capacitors}

3D nanostructured hybrid materials, with better interfacial contact and volume utilization, have stimulated the development of several energy-efficient technologies via in situ polymerization of aniline onto a porous CNF/GO template (Figure 15). Such materials can be used for the facile fabrication of 3D PANI-modified CNF/GO hybrid electrodes, with the template imparting excellent conductivity and flexibility to the electrodes [103]. Specifically, CNFs significantly reduce the aggregation degree of GO, thereby forming a porous structure, which in turn substantially improves the utilization surface of GO. The in situ facial deposition process results in 3D hierarchically nanostructured PANI/CNF/GO composite electrodes with unique acanthine-style PANI nanowires covering the CNF/GO supports. PPy and other conducting polymers and metal oxides can also be used in hybrid capacitors $[104,105]$.

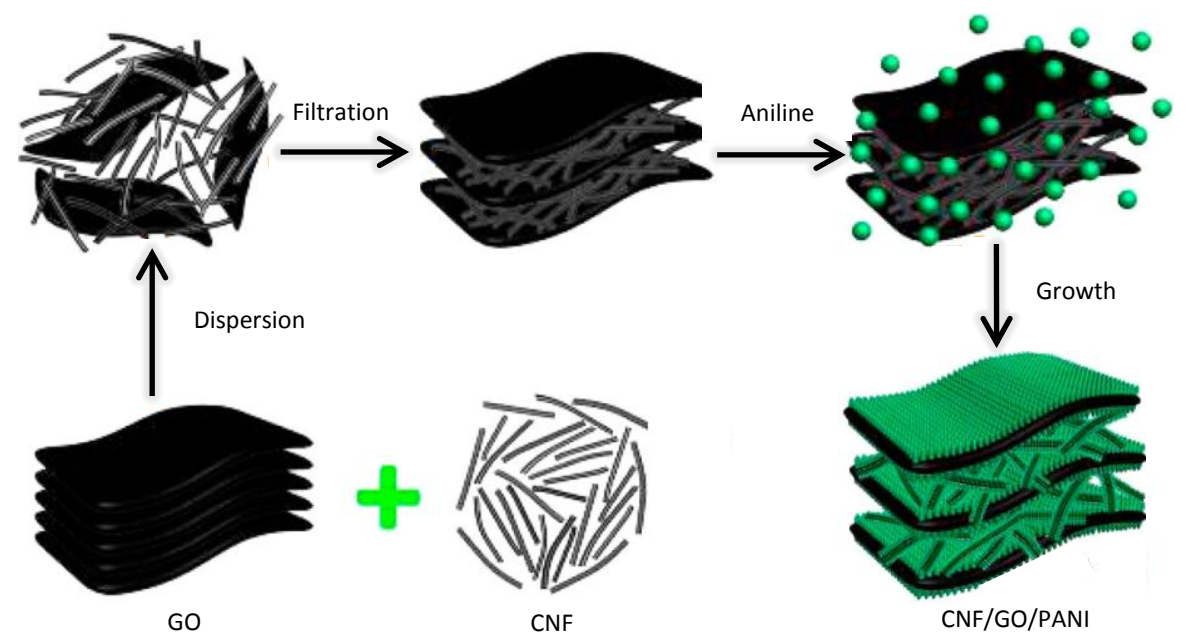

Figure 15. Formation mechanism of the CNF/GO/PANI film. With permission from [103];

Copyright 2013, American Chemical Society. 
A 3D hierarchical graphene/PPy aerogel (GPA) was fabricated using GO and 1D PPy nanotubes [106]. The as-formed GPAs exhibited low density, large specific surface area, and high compressive strength, which are highly desired properties in porous materials. Moreover, the 1D nanotube geometry facilitated electron transport and allowed relatively larger surface areas than nanorods and nanowires. The aerogel contributed to the low density and formation of pore structures. The double-pore structure (between graphene-graphene sheets and in PPy) had a large surface area and exhibited outstanding electrochemical performance. Such 3D porous nanostructures have advantages in terms of the facile diffusion of electrolyte ions into and out of the inner region of the active materials and effective surface-area utilization [107]. Thus, it is expected that the 3D electrode structure of graphene-based hybrid capacitors will show a synergetic effect caused by materials hybridization and a unique hierarchical structure [108,109].

Another interesting example is a composite of PPy nanowires intercalated with RGO sheets (Figure 16) [110]. The intercalated PPy nanowires prevent restacking of the graphene sheets and allow the formation of an open 3D architecture for electrolytes. The combination of conducting polymers and graphene has led to rapid development of high capacitance for flexible electrochemical capacitors [111,112].

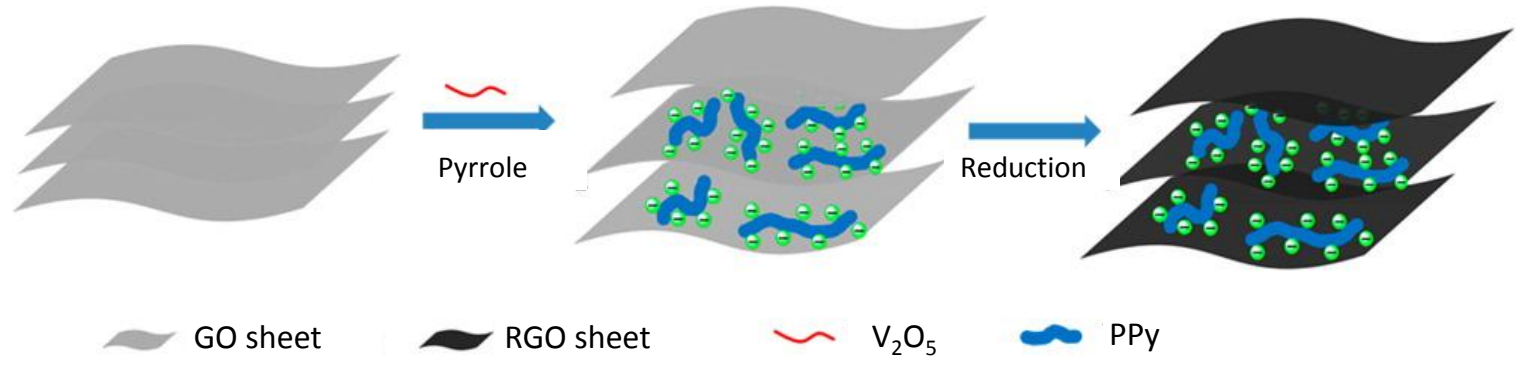

Figure 16. Scheme showing the synthetic route of PPy/RGO composites. With permission from [110]; Copyright 2014, American Chemical Society.

\subsection{Summary}

The electrochemical performance of pseudocapacitive conducting polymers and metal oxides can be improved through combinations with carbon materials. Table 3 summarizes the electrode materials for hybrid capacitors and their electrochemical performance. Vigorous on-going research and development are aimed at improving both the energy and power densities. However, the following issues should be further considered in the practical application of hybrid capacitors: the (i) different charge/discharge rates of EDLCs and pseudocapacitive materials and (ii) unstable charge/discharge cycling performance. 
Table 3. Hybrid capacitor materials and electrochemical performance.

\begin{tabular}{|c|c|c|c|c|c|c|}
\hline Materials ${ }^{(1)}$ & $\begin{array}{l}\text { Electrode } \\
\text { System }^{(2,3)}\end{array}$ & Electrolyte & $\begin{array}{c}\text { Current } \\
\text { Density or } \\
\text { Scan Rate } \\
\end{array}$ & $\begin{array}{c}\text { Potential } \\
\text { Range } \\
\text { (V) }\end{array}$ & $\begin{array}{c}\text { Specific } \\
\text { capacitance } \\
\left(\mathbf{F} \cdot \mathbf{g}^{-1}\right) \\
\end{array}$ & Ref. \\
\hline $\mathrm{NiO} /$ graphene & Two & $1 \mathrm{M} \mathrm{NaOH}$ & $7-20 \mathrm{~A} \cdot \mathrm{g}^{-1}$ & 1.5 & $130-440$ & 13 \\
\hline Porous carbon/ $\mathrm{Fe}_{2} \mathrm{O}_{3}$ nanoparticles & Three & $1 \mathrm{M} \mathrm{Na}_{2} \mathrm{SO}_{3}$ & $0.5-10 \mathrm{~A} \cdot \mathrm{g}^{-1}$ & 1.0 & $119-235$ & 14 \\
\hline$\alpha-\mathrm{Fe}_{2} \mathrm{O}_{3} /$ Graphene & Three & $1 \mathrm{M} \mathrm{Na}_{2} \mathrm{SO}_{4}$ & $3-10 \mathrm{~A} \cdot \mathrm{g}^{-1}$ & 1.0 & $98-306$ & 15 \\
\hline Ni graphene aerogels & Two & $6 \mathrm{M} \mathrm{KOH}$ & $2-20 \mathrm{~A} \cdot \mathrm{g}^{-1}$ & 1.0 & $186-366$ & 85 \\
\hline $\mathrm{CoO}$ carbon nanoflakes & Three & $2 \mathrm{M} \mathrm{KOH}$ & $10 \mathrm{~mA} \cdot \mathrm{cm}^{-2}$ & 0.75 & 476 & 86 \\
\hline Faradaic CNTs & Three & $0.5 \mathrm{M} \mathrm{H}_{2} \mathrm{SO}_{4}$ & $3-100 \mathrm{mV} \cdot \mathrm{s}^{-1}$ & 0.9 & $75-260$ & 87 \\
\hline Nanoporous $\mathrm{CuO} /$ active carbon & Two & $3 \mathrm{M} \mathrm{KOH}$ & $1-10 \mathrm{~A} \cdot \mathrm{g}^{-1}$ & 1.4 & $54-72$ & 88 \\
\hline $\mathrm{Co}(\mathrm{OH})_{2} /$ graphene & Three & $6 \mathrm{M} \mathrm{KOH}$ & $2-10 \mathrm{~A} \cdot \mathrm{g}^{-1}$ & 0.7 & $356-532$ & 89 \\
\hline PANI/RGO & Three & $1 \mathrm{M} \mathrm{H}_{2} \mathrm{SO}_{4}$ & $0.45 \mathrm{~A} \cdot \mathrm{g}^{-1}$ & 0.8 & 431 & 90 \\
\hline $\mathrm{PANI} / \mathrm{CNF}$ & Three & $1 \mathrm{M} \mathrm{H}_{2} \mathrm{SO}_{4}$ & $0.3-10 \mathrm{~A} \cdot \mathrm{g}^{-1}$ & 1.2 & $400-557$ & 91 \\
\hline PANI/N-doped CNTs & Three & $0.1 \mathrm{M} \mathrm{Na}_{2} \mathrm{SO}_{4}$ & $50 \mathrm{mV} \cdot \mathrm{s}^{-1}$ & 1.0 & 250 & 92 \\
\hline PPy/graphene & Two & $1 \mathrm{M} \mathrm{H}_{2} \mathrm{SO}_{4}$ & $0.1 \mathrm{~A} \cdot \mathrm{g}^{-1}$ & 1.0 & 277 & 94 \\
\hline $\mathrm{Ni}-\mathrm{Mn}-\mathrm{RGO}$ & Two & $1 \mathrm{M} \mathrm{KOH}$ & $2-10 \mathrm{~A} \cdot \mathrm{g}^{-1}$ & 1.6 & $724-1985$ & 95 \\
\hline $3 \mathrm{D}$ carbon $/ \mathrm{CoNi}_{3} \mathrm{O}_{4}$ asymmetric & Two & $3 \mathrm{M} \mathrm{KOH}$ & $1-100 \mathrm{~mA} \cdot \mathrm{cm}^{-2}$ & 1.8 & $42-64$ & 96 \\
\hline$N$-doped carbon/PANI asymmetric & Two & $1 \mathrm{M} \mathrm{Na}_{2} \mathrm{SO}_{4}$ & $0.5-20 \mathrm{~A} \cdot \mathrm{g}^{-1}$ & 1.1 & $75-113$ & 97 \\
\hline $\mathrm{WO}_{3} / \mathrm{PPy}$ nanowire asymmetric & Three & $3 \mathrm{M} \mathrm{NaOH}$ & $0.7-7 \mathrm{~mA} \cdot \mathrm{cm}^{-2}$ & 0.6 & $250-800$ & 98 \\
\hline $\begin{array}{c}\mathrm{Mn}-\mathrm{Ni}-\mathrm{Co} \text { oxide nanowire/RGO } \\
\text { asymmetric }\end{array}$ & Three & $6 \mathrm{M} \mathrm{KOH}$ & $1-20 \mathrm{~A} \cdot \mathrm{g}^{-1}$ & 0.5 & $404-638$ & 99 \\
\hline PEDOT/ROG/CNF asymmetric & Two & $1 \mathrm{M} \mathrm{H}_{2} \mathrm{SO}_{4}$ & $0.1-2 \mathrm{~A} \cdot \mathrm{g}^{-1}$ & 1.0 & $50-60$ & 100 \\
\hline $\mathrm{MnO}_{2} / \mathrm{GO}$ asymmetric & Two & $1 \mathrm{M} \mathrm{Na}_{2} \mathrm{SO}_{4}$ & $0.1-2 \mathrm{~A} \cdot \mathrm{g}^{-1}$ & 2.0 & $41-84$ & 101 \\
\hline $\mathrm{RGO} / \mathrm{MnO}_{2}$ asymmetric & Three & $1 \mathrm{M} \mathrm{Na}_{2} \mathrm{SO}_{4}$ & $0.1-1 \mathrm{~A} \cdot \mathrm{g}^{-1}$ & 1.5 & $217-243$ & 102 \\
\hline CNF/GO/PANI & Two & $1 \mathrm{M} \mathrm{H}_{2} \mathrm{SO}_{4}$ & $2 \mathrm{~A} \cdot \mathrm{g}^{-1}$ & 0.8 & 479 & 103 \\
\hline Ni/graphene/CNT & Two & $6 \mathrm{M} \mathrm{KOH}$ & $0.2-1.0 \mathrm{~A} \cdot \mathrm{g}^{-1}$ & 0.8 & $100-105$ & 104 \\
\hline Graphene/PANI nanorods & Three & $1 \mathrm{M} \mathrm{H}_{2} \mathrm{SO}_{4}$ & $1-8 \mathrm{~A} \cdot \mathrm{g}^{-1}$ & 0.7 & $836-1665$ & 106 \\
\hline 3D CoMoO$/$ graphene & Three & $2 \mathrm{M} \mathrm{KOH}$ & $1.5-85 \mathrm{~A} \cdot \mathrm{g}^{-1}$ & 0.9 & $1101-2741$ & 108 \\
\hline Graphene/CNT/Mn & Two & $2 \mathrm{M} \mathrm{Li}_{2} \mathrm{SO}_{4}$ & $1.9 \mathrm{~A} \cdot \mathrm{g}^{-1}$ & 1.6 & 1108 & 109 \\
\hline PPy nanowire/RGO & Two & $\mathrm{PVA}-\mathrm{H}_{2} \mathrm{SO}_{4}$ gel & $1-20 \mathrm{~A} \cdot \mathrm{g}^{-1}$ & 0.8 & $361-434$ & 110 \\
\hline Porous graphene/PANI & Two & $1 \mathrm{M} \mathrm{H}_{2} \mathrm{SO}_{4}$ & $1-8 \mathrm{~A} \cdot \mathrm{g}^{-1}$ & 0.8 & $458-864$ & 111 \\
\hline Porous graphene/PANI & Two & $1 \mathrm{M} \mathrm{H}_{2} \mathrm{SO}_{4}$ & $0.5-10 \mathrm{~A} \cdot \mathrm{g}^{-1}$ & 0.7 & $362-385$ & 112 \\
\hline
\end{tabular}

(1) The term "asymmetric" is given when the capacitor cell has a cathode and an anode consisting of different materials, namely asymmetric electrode configuration. (2) The "Two" indicates capacitor cells composed of two electrodes (anode/cathode), separator, and electrolyte, containing symmetric or asymmetric electrode configurations. ${ }^{(3)}$ The "Three" indicates electrode measuring systems composed of working electrode, counter electrode, and reference electrode in an electrolyte.

\section{Outlook}

Exploration of better electrode materials has been extensive over the few past decades. First, the surface area of the electrode/electrolyte interface must be increased in order to enhance the charge storage capacity in EDLCs. The use of a porous electrode with a higher specific surface area may increase the specific capacitance of an EDLC. Since ion desolvation occurs in pores smaller than the solvated ions, increased capacitance can be obtained from electrode materials with sub-nano-size pores. Meso- or macro-pores ensure the accessibility of ions. Thus, there have been many attempts to develop 
hierarchical nanoarchitectures with both micro- and macro-pores, in hope of fabricating better electrochemical capacitors. Although they are capable of providing high power for long cycles, EDLCs have a relatively low energy density. Therefore, future development is projected to still focus on the optimization of existing electrode materials and the creation of new materials for achieving energy densities approaching those of batteries.

Pseudocapacitors have significantly higher faradaic capacitance than double-layer capacitance. In general, conducting polymers and metal oxides render pseudocapacitance via a faradaic reaction. Enhancing the surface area of electrode materials is still an important factor in pseudocapacitors, as it is with EDLCs. In most cases, the faradaic reaction for pseudocapacitance occurs at the surface of the electrode materials. Nanostructured pseudocapacitive materials with increased surface area, therefore, have been developed and their morphology has been precisely tailored. Typically, fibrous and tubular materials exhibit higher capacitance than other morphologies. Combining different pseudocapacitive nanomaterials can result in excellent electrodes with improved electrochemical performance. However, the excellent performance of pseudocapacitors tends to degrade quickly upon cycling.

Various hybrid capacitors have been demonstrated as attractive alternatives to only EDLCs or only pseudocapacitors. The drawbacks of conventional EDLCs and pseudocapacitors, such as limited energy density and poor cycling stability, can be overcome by employing rational hybrid systems of pseudocapacitor (faradaic)-like and EDLC (nonfaradaic)-like electrodes, thereby producing a high working voltage and capacitance. There is growing demand for the development of electrochemical capacitors whose performance exceeds that of batteries. Nanomaterial-based hybrid capacitors have the potential to fulfill these requirements.

As a result, it is expected that future extensive research into nanomaterial-based electrochemical capacitors will offer great potential for the construction of next-generation energy storage devices. In particular, the development of nanomaterial-based wearable or flexible high-performance electrochemical capacitors is expected in the near future.

In this review, we have focused on nanostructured electrode materials. However, in addition to electrode materials, several factors such as electrolytes, separators, and binders also significantly influence the performance of electrochemical capacitors. First, different types of electrolytes, which are based on aqueous solutions, organic solvents, and ionic liquids, have been used in electrochemical capacitors. In general, aqueous gel electrolytes operate within a narrow potential range with a maximum of $1 \mathrm{~V}$, leading to low cell voltage, which in turn limits energy and power densities. Moreover, water evaporation during the operation of these electrolytes over a wide temperature range negatively affects the performance and long-term stability of the devices. Ionic liquid gels, in contrast, are thermally stable, nonvolatile, nonflammable, and nontoxic over a wide potential range of $3.5 \mathrm{~V}$. Sometimes, redox mediators can be introduced into the electrolyte to facilitate the redox reaction, thereby increasing the pseudocapacitance [113]. Likewise, electrochemical capacitors mostly use solution-phase electrolytes, which are prone to leaking. Recently, flexible, wearable electrochemical capacitors have been of particular interest as a mobile power supply for future flexible electronics. However, electrolyte leaking can be problematic in these flexible or wearable devices. All solid-state electrochemical capacitors, in which electrolyte gels function as the separator, can be an alternative to circumvent electrolyte leaking.

Nonconductive polymers such as polyvinylidene fluoride and polytetrafluoroethylene are widely used as binders to construct electrodes. These polymers facilitate good adhesion between electrode materials 
or between electrode materials and current collectors. However, intrinsically, they are insulators and thus function as resistances that degrade the electrode performance. To circumvent this problem, conductive fillers have been introduced into the insulating polymers. However, it is difficult to achieve uniform dispersion of the fillers in the polymer matrix for obtaining desirable properties. Notably, an intrinsically conductive solution-processable PANI binder has very recently been prepared, in which PANI was treated with three organic additives as a ternary dopant [114]. The resulting PANI binders had abundant oxygenated functional groups such as sulfonate and hydroxyl groups, which facilitated ion transport. The polar groups of the additives provide adhesive properties via hydrogen-bonding or dipole-dipole interactions. The substituted alkyl chain may further afford adhesive properties to nonpolar surfaces through van der Waals interactions. Consequently, the PANI binders showed good conductivity and adhesive properties without the use of additional conductive fillers or heat treatment. Figure 17 shows the performance of a PANI binder in detail. PANI as a binder was found to significantly enhance the electrode performance of pseudocapacitive (PPy nanospheres and PANI nanofibrils) and EDLC (carbon black) nanomaterials. There is a still need for developing alternative efficient electrode binders capable of improving the device performance.

a)

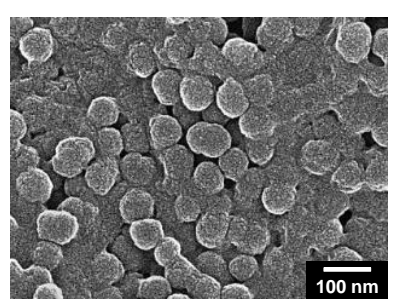

b)

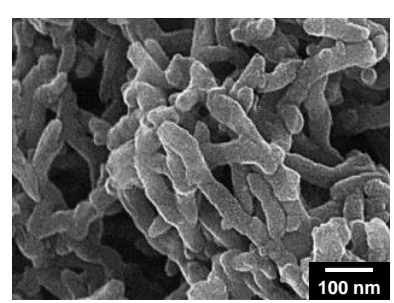

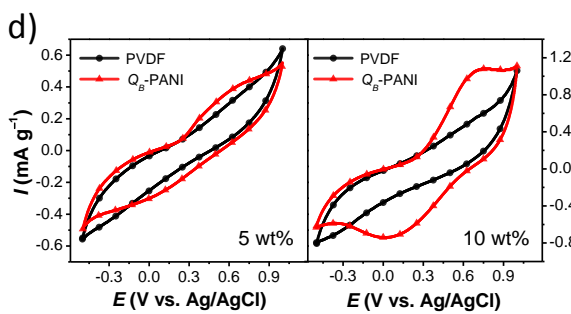

e)
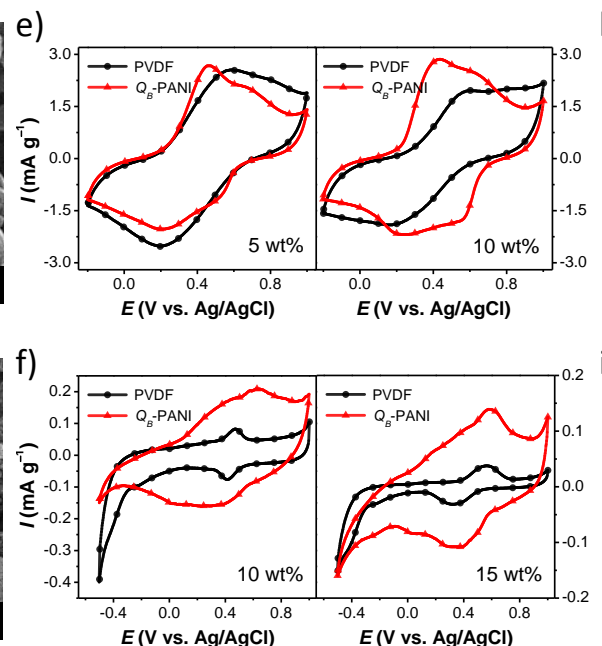

$E(\mathrm{~V}$ vs. Ag/AgCl)
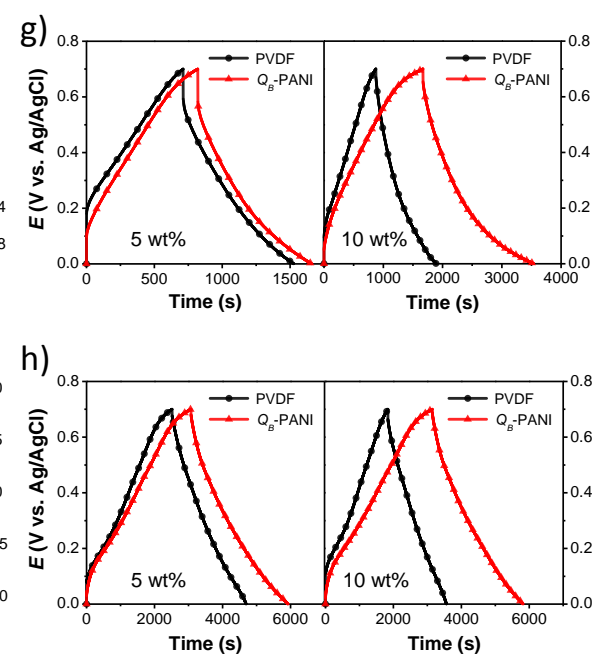

c)
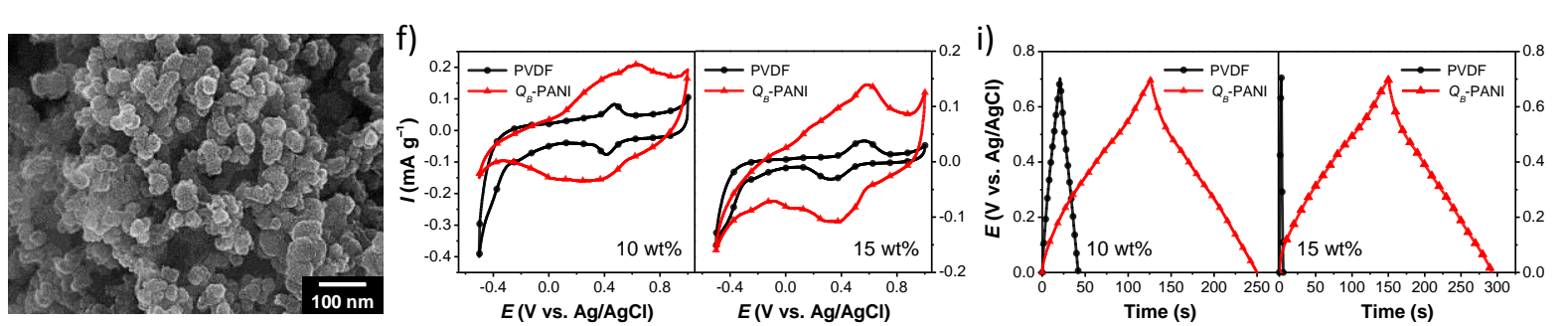

Figure 17. Cont. 

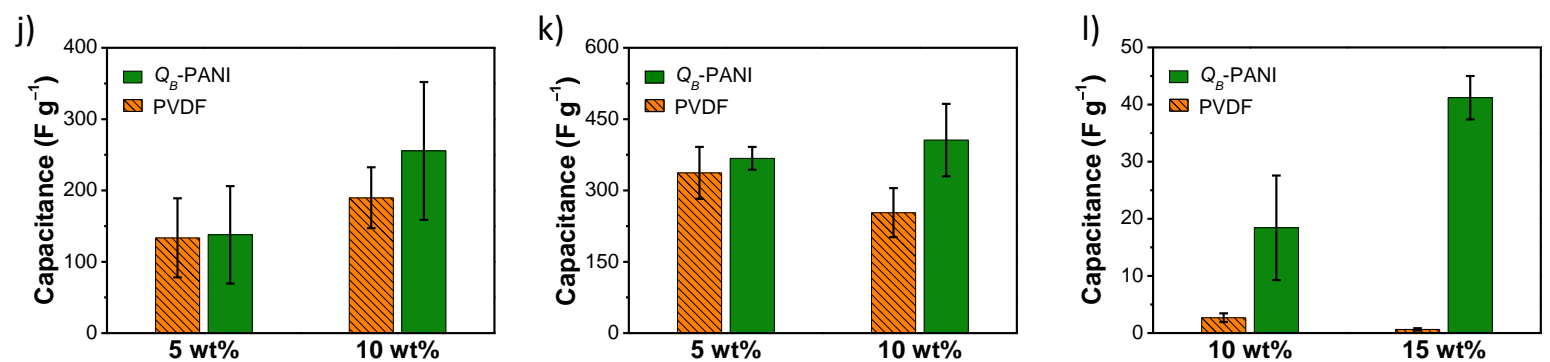

Figure 17. Electrode binder performance of an intrinsically conductive PANI glue: SEM images of nanoparticle electrodes prepared with a 10 wt.\% PANI binder content: (a) PPy nanospheres, (b) PANI nanofibrils, and (c) carbon black. Representative CV curves and galvanostatic charge-discharge curves of the electrodes recorded at a scan rate of $25 \mathrm{mV} \cdot \mathrm{s}^{-1}$ and a current density of $0.1 \mathrm{~A} \cdot \mathrm{g}^{-1}$, respectively, in $1 \mathrm{M}$ sulfuric acid: (d and g) PPy nanospheres, (e and h) PANI nanofibrils (5 wt.\% and 10 wt.\% binder contents), and (f and i) carbon black electrodes with $10 \mathrm{wt} . \%$ and $15 \mathrm{wt} . \%$ binder. Gravimetric discharge capacitances calculated from the charge-discharge curves are presented in the histograms: (j) PPy nanospheres, (k) PANI nanofibrils, and (l) carbon black. With permission from [114]; Copyright 2014, The Royal Society of Chemistry.

Additionally, the performance of electrochemical capacitors also depends on the microarrangement of the electrode materials in the cell. For example, capacitor applications are often constrained by volume rather than by weight. Unfortunately, nanomaterial-based electrochemical capacitors typically exhibit low volumetric capacitance. Therefore, increasing the packing density of nanomaterials inside the electrode is one of the critical issues in electrochemical capacitor research.

In summary, there are key challenges to achieving advances in electrochemical capacitor research:

(i) control of the 3D structure of electrode materials in the nanometer regime,

(ii) battery-like hybrid capacitors with both high energy and power densities,

(iii) flexible, all-solid-state devices,

(iv) use of intrinsically conductive binders or no binder,

(v) increased volumetric capacitance.

In conclusion, the electrochemical capacitor market continues to grow and expand into a greater number of applications. Continuous research on electrode materials, cell assembly, and entire cell systems should yield electrochemical capacitors that exhibit the excellent properties of both conventional capacitors and batteries and might ultimately facilitate the emergence of new types of energy storage devices.

\section{Acknowledgments}

This research was supported by Basic Science Research Program (NRF-2012R1A1A1042024) through the National Research Foundation of Korea (NRF) funded by the Ministry of Science, ICT, and Future Planning. 


\section{Conflicts of Interest}

The authors declare no conflict of interest.

\section{References}

1. Faraji, S.; Ani, F.N. The development supercapacitor from activated carbon by electroless plating-A review. Renew. Sustain. Energy Rev. 2015, 42, 823-834.

2. Pandolfo, T.; Ruiz, V.; Sivakkumar, S.; Nerkar, J. Supercapacitors: Materials, Systems, and Applications; Wiley-VCH Verlag GmbH \& Co. KgaA: Weinheim, Germany, 2013; pp. 69-109.

3. Chen, Z.; Yu, D.; Xiong, W.; Liu, P.; Liu, Y.; Dai, L. Graphene-based nanowire supercapacitors. Langmuir 2014, 30, 3567-3571.

4. Simon, P.; Taberna, P.-L.; Béguin, F. Supercapacitors: Materials, Systems, and Applications; Wiley-VCH Verlag GmbH \& Co. KgaA: Weinheim, Germany, 2013; pp. 131-165.

5. Wang, G.; Zhang, L.; Zhang, J. A review of electrode materials for electrochemical supercapacitors. Chem. Soc. Rev. 2012, 41, 797-828.

6. Hou, J.; Cao, C.; Idrees, F.; Ma, X. Hierarchical porous nitrogen-doped carbon nanosheets derived from silk for ultrahigh-capacity battery anodes and supercapacitors. ACS Nano 2015, 9, 2556-2564.

7. Chen, T.; Peng, H.; Durstock, M.; Dai, L. High-performance transparent and stretchable all-solid supercapacitors based on highly aligned carbon nanotube sheets. Sci. Rep. 2014, 4, 3612.

8. Li, Y.; Dong, J.; Zhang, J.; Zhao, X.; Yu, P.; Jin, L.; Zhang, Q. Nitrogen-doped carbon membrane derived from polyimide as free-standing electrodes for flexible supercapacitors. Small 2015, 11, doi:10.1002/smll.201403575.

9. Chen, K.; Yang, Y.; Li, K.; Ma, Z.; Zhou, Y.; Xue, D. $\mathrm{CoCl}_{2}$ designed as excellent pseudocapacitor electrode materials. ACS Sustain. Chem. Eng. 2014, 2, 440-444.

10. Chen, W.; Rakhi, R.B.; Alshareef, H.N. Morphology-dependent enhancement of the pseudocapacitance of template-guided tunable polyaniline nanostructures. J. Phys. Chem. C 2013, 117, 15009-15019.

11. Shao, M.; Li, Z.; Zhang, R.; Ning, F.; Wei, M.; Evans, D.G.; Duan, X. Hierarchical conducting polymer@clay core-shell arrays for flexible all-solid-state supercapacitor devices. Small 2015, doi:10.1002/smll.201403421.

12. Nejati, S.; Minford, T.E.; Smolin, Y.Y.; Lau, K.K.S. Enhanced charge storage of ultrathin polythiophene films within porous nanostructures. ACS Nano 2014, 8, 5413-5422.

13. Terasawa, N.; Asaka, K. High-performance hybrid (electrostatic double-layer and faradaic capacitor-based) polymer actuators incorporating nickel oxide and vapor-grown carbon nanofibers. Langmuir 2014, 30, 14343-14351.

14. Lin, Y.; Wang, X.; Qian, G.; Watkins, J.J. Additive-driven self-assembly of well-ordered mesoporous carbon/iron oxide nanoparticle composites for supercapacitors. Chem. Mater. 2014, 26, 2128-2137.

15. Yang, S.; Song, X.; Zhang, P.; Sun, J.; Gao, L. Self-assembled $\alpha-\mathrm{Fe}_{2} \mathrm{O}_{3}$ mesocrystals/graphene nanohybrid for enhanced electrochemical capacitors. Small 2014, 10, 2270-2279. 
16. Zhang, J.; Zhang, X.; Zhou, Y.; Guo, S.; Wang, K.; Liang, Z.; Xu, Q. Nitrogen-doped hierarchical porous carbon nanowhisker ensembles on carbon nanofiber for high-performance supercapacitors. ACS Sustain. Chem. Eng. 2014, 2, 1525-1533.

17. Chen, X.Y.; Chen, C.; Zhang, Z.J.; Xie, D.H.; Deng, X. Nitrogen-doped porous carbon prepared from urea formaldehyde resins by template carbonization method for supercapacitors. Ind. Eng. Chem. Res. 2013, 52, 10181-10188.

18. Liu, W.J.; Tian, K.; He, Y.-R.; Jiang, H.; Yu, H.Q. High-yield harvest of nanofibers/mesoporous carbon composite by pyrolysis of waste biomass and its application for high durability electrochemical energy storage. Environ. Sci. Technol. 2014, 48, 13951-13959.

19. Chen, X.Y.; Chen, C.; Zhang, Z.J.; Xie, D.H. Nitrogen-doped porous carbon spheres derived from polyacrylamide. Ind. Eng. Chem. Res. 2013, 52, 12025-12031.

20. Chen, J.; Li, C.; Shi, G. Graphene materials for electrochemical capacitors. J. Phys. Chem. Lett. 2013, 4, 1244-1253.

21. Vu, A.; Li, X.; Phillips, J.; Han, A.; Smyrl, W.H.; Bühlmann, P.; Stein, A. Three-dimensionally ordered mesoporous (3DOm) carbon materials as electrodes for electrochemical double-layer capacitors with ionic liquid electrolytes. Chem. Mater. 2013, 25, 4137-4148.

22. Cho, K.T.; Lee, S.B.; Lee, J.W. Facile synthesis of highly electrocapacitive nitrogen-doped graphitic porous carbons. J. Phys. Chem. C 2014, 118, 9357-9367.

23. Fedorov, M.V.; Kornyshev, A.A. Ionic liquids at electrified interfaces. Chem. Rev. 2014, 114, 2978 3036.

24. Fuertes, A.B.; Sevilla, M. Hierarchical microporous/mesoporous carbon nanosheets for high-performance supercapacitors. ACS Appl. Mater. Interfaces 2015, 7, 4344-4353.

25. Yang, X.; Zhang, F.; Zhang, L.; Zhang, T.; Huang, Y.; Chen, Y. A High-performance graphene oxide-doped ion gel as gel polymer electrolyte for all-solid-state supercapacitor applications. Adv. Funct. Mater. 2013, 23, 3353-3360.

26. Yao, Y.; Ma, C.; Wang, J.; Qiao, W.; Ling, L.; Long, D. Rational design of high-surface-area carbon nanotube/microporous carbon core-shell nanocomposites for supercapacitor electrodes. ACS Appl. Mater. Interfaces 2015, 7, 4817-4825.

27. Richey, F.W.; Tran, C.; Kalra, V.; Elabd, Y.A. Ionic liquid dynamics in nanoporous carbon nanofibers in supercapacitors measured with in operando infrared spectroelectrochemistry. J. Phys. Chem. C 2014, 118, 21846-21855.

28. Chen, X.; Wang, H.; Yi, H.; Wang, X.; Yan, X.; Guo, Z. Anthraquinone on porous carbon nanotubes with improved supercapacitor performance. J. Phys. Chem. C, 2014, 118, 8262-8270.

29. You, B.; Jiang, J.; Fan, S. Three-dimensional hierarchically porous all-carbon foams for supercapacitor. ACS Appl. Mater. Interfaces 2014, 6, 15302-15308.

30. Qin, Z.; Taylor, M.; Hwang, M.; Bertoldi, K.; Buehler, M.J. Effect of wrinkles on the surface area of graphene: Toward the design of nanoelectronics. Nano Lett. 2014, 14, 6520-6525.

31. Chen, X.; Qiu, L.; Ren, J.; Guan, G.; Lin, H.; Zhang, Z.; Chen, P.; Wang, Y.; Peng, H. Novel electric double-layer capacitor with a coaxial fiber structure. Adv. Mater. 2013, 25, 6436-6441.

32. Krishnan, D.; Raidongia, K.; Shao, J.; Huang, J. Graphene oxide assisted hydrothermal carbonization of carbon hydrates. ACS Nano 2014, 8, 449-457. 
33. Matsumoto, H.; Imaizumi, S.; Konosu, Y.; Ashizawa, M.; Minagawa, M.; Tanioka, A.; Lu, W.; Tour, J.M. Electrospun composite nanofiber yarns containing oriented graphene nanoribbons. ACS Appl. Mater. Interfaces 2013, 5, 6225-6231.

34. Deng, L.; Young, R.J.; Kinloch, J.A.; Abdelkader, A.M.; Holmes, S.M.; Rio, D.A.; Eichhorn, S.J. Supercapacitance from cellulose and carbon nanotube nanocomposite fibers. ACS Appl. Mater. Interfaces 2013, 5, 9983-9990.

35. Zhang, J.; Wang, K.; Guo, S.; Wang, S.; Liang, Z.; Chen, Z.; Fu, J.; Xu, Q. One-step carbonization synthesis of hollow carbon nanococoons with multimodal pores and their enhanced electrochemical performance for supercapacitors. ACS Appl. Mater. Interfaces 2014, 6, 2192-2198.

36. Wilson, E.; Islam, M.F. Ultracompressible, high-rate supercapacitors from graphene-coated carbon nanotube aerogels. ACS Appl. Mater. Interfaces 2015, 7, 5612-5618.

37. Stoner, B.R.; Raut, A.S.; Brown, B.; Parker, C.B.; Glass, J.T. Graphenated carbon nanotubes for enhanced electrochemical double layer capacitor performance. Appl. Phys. Lett. 2011, 99, 183104.

38. Yu, K.; Lu, G.; Bo, Z.; Mao, S.; Chen, J. Carbon nanotube with chemically bonded graphene leaves for electronic and optoelectronic applications. J. Phys. Chem. Lett. 2011, 2, 1556-1562.

39. Kwon, O.S.; Kim, T.; Lee, J.S.; Park, S.J.; Park, H.-W.; Kang, M.; Lee, J.E.; Jang, J.; Yoon, H. Fabrication of graphene sheets intercalated with manganese oxide/carbon nanofibers: Toward highcapacity energy storage. Small 2013, 9, 248-254.

40. Li, Y.; Li, Z.; Shen, P.K. Simultaneous formation of ultrahigh surface area and three-dimensional hierarchical porous graphene-like networks for fast and highly stable supercapacitors. Adv. Mater. 2013, 25, 2474-2480.

41. Lee, J.-S.; Kim, S.-I.; Yoon, J.-C.; Jang, J.-H. Chemical vapor deposition of mesoporous graphene nanoballs for supercapacitor. ACS Nano 2013, 7, 6047-6055.

42. Sun, H.; You, X. Deng, J.; Chen, X.; Yang, Z.; Ren, J.; Peng, H. Novel graphene/carbon nanotube composite fibers for efficient wire-shaped miniature energy devices. Adv. Mater. 2014, 26, 2868-2873.

43. Peng, H.; Ma, G.; Sun, K.; Mu, J.; Zhang, Z.; Lei, Z. Facile synthesis of poly( $p$-phenylenediamine)derived three-dimensional porous nitrogen-doped carbon networks for high performance supercapacitors. J. Phys. Chem. C 2014, 118, 29507-29516.

44. Pham, D.T.; Lee, T.H.; Luong, D.H.; Yao, F.; Ghosh, A.; Le, V.T.; Kim, T.H.; Li, B.; Chang, J.; Lee, Y.H. Carbon nanotube-bridged graphene 3D building blocks for ultrafast compact supercapacitors. ACS Nano 2015, 9, 2018-2027.

45. Yang, X.; Zhang, L.; Zhang, F.; Zhang, T.; Huang, Y.; Chen, Y. A high-performance all-solid-state supercapacitor with graphene-doped carbon material electrodes and a graphene oxide-doped ion gel electrolyte. Carbon 2014, 72, 381-386.

46. Zheng, Q.; Cai, Z.; Ma, Z.; Gong, S. Cellulose nanofibril/reduced graphene oxide/carbon nanotube hybrid aerogels for highly flexible and all-solid-state supercapacitors. ACS Appl. Mater. Interfaces 2015, 7, 3263-3271.

47. Huang, X.; Kim, S.; Heo, M.S.; Kim, J.E.; Suh, H.; Kim, I. Easy synthesis of hierarchical carbon spheres with superior capacitive performance in supercapacitors. Langmuir 2013, 29, 12266-12274. 
48. Ćirić-Marjanović, C.; Mentus, S.; Pašti, I.; Gavrilov, N.; Krstić, J.; Travas-Sejdic, J.; Strover, L.T.; Kopecká, J.; Moravková, Z.; Trchová, M.; et al. Synthesis, characterization, and electrochemistry of nanotubular polypyrrole and polypyrrole-derived carbon nanotubes. J. Phys. Chem. C 2014, 118, 14770-14784.

49. Chen, X.Y.; Cheng, L.X.; Deng, X.; Zhang, L.; Zhang, Z.J. Generalized conversion of halogen-containing plastic waste into nanoporous carbon by a template carbonization method. Ind. Eng. Chem. Res. 2014, 53, 6990-6997.

50. Zhao, Y.; Ran, W.; He, J.; Song, Y.; Zhang, C.; Xiong, D.-B.; Gao, F.; Wu, J.; Xia, Y. Oxygen-rich hierarchical porous carbon derived from artemia cyst Shells with superior electrochemical performance. ACS Appl. Mater. Interfaces 2015, 7, 1132-1139.

51. Singh, A.K.; Sarkar, D.; Khan, G.G.; Mandal, K. Hydrogenated NiO nanoblock architecture for high performance pseudocapacitor. ACS Appl. Mater. Interfaces 2014, 6, 4684-4692.

52. Chang, Y.; Liu, Z.; Fu, Z.; Wang, C.; Dai, Y.; Peng, R.; Hu, X. Preparation and characterization of one-dimensional core-shell sepiolite/polypyrrole nanocomposites and effect of organic modification on the electrochemical properties. Ind. Eng. Chem. Res. 2014, 53, 38-47.

53. Liu, B.; Liu, B.; Wang, Q.; Wang, X.; Xiang, Q.; Chen, D.; Shen, G. New energy storage option: Toward $\mathrm{ZnCo}_{2} \mathrm{O}_{4}$ nanorods/nickel foam architectures for high-performance supercapacitors. ACS Appl. Mater. Interfaces 2013, 5, 10011-10017.

54. Shang, C.; Dong, S.; Wang, S.; Xiao, D.; Han, P.; Wang, X.; Gu, L.; Cui, G. Coaxial $\mathrm{Ni}_{x} \mathrm{Co}_{2 x}(\mathrm{OH})_{6 x} / \mathrm{TiN}$ nanotube arrays as supercapacitor electrodes. ACS Nano 2013, 7, 5430-5436.

55. Zhang, J.; Fu, J.; Zhang, J.; Ma, H.; He, Y.; Li, F.; Xie, E.; Xue, D.; Zhang, H.; Peng, Y. Co@Co3O4 core-shell three-dimensional nano-network for high-performance electrochemical energy storage. Small 2014, 10, 2618-2624.

56. Zhu, G.; Xi, C.; Shen, M.; Bao, C.; Zhu, J. Nanosheet-based hierarchical $\mathrm{Ni}_{2}\left(\mathrm{CO}_{3}\right)(\mathrm{OH})_{2}$ microspheres with weak crystallinity for high-performance supercapacitor. ACS Appl. Mater. Interfaces 2014, 6, 17208-17214.

57. Yoon, H.; Choi, M.; Lee, K.J.; Jang, J. Versatile strategies for fabricating polymer nanomaterials with controlled size and morphology. Macromol. Res. 2008, 16, 85-102.

58. Wang, Z.-L.; He, X.-J.; Ye, S.-H.; Tong, Y.-X.; Li, G.-R. Design of polypyrrole/polyaniline double-walled nanotube arrays for electrochemical energy storage. ACS Appl. Mater. Interfaces 2014, 6, 642-647.

59. Park, S.J.; Kwon, O.S.; Lee, J.E.; Jang, J.; Yoon, H. Conducting polymer-based nanohybrid transducers: A potential route to high sensitivity and selectivity sensors. Sensors 2014, 14, 3604-3630.

60. Yoon, H. Current trends in sensors based on conducting polymer nanomaterials. Nanomaterials 2013, 3, 524-549.

61. Park, H.-W.; Kim, T.; Huh, J.; Kang, M.; Lee, J.E.; Yoon, H. Anisotropic growth control of polyaniline nanostructures and their morphology-dependent electrochemical characteristics. ACS Nano 2012, 6, 7624-7633.

62. Arcila-Velez, M.R.; Roberts, M.E. Redox solute doped polypyrrole for high-charge capacity polymer electrodes. Chem. Mater. 2014, 26, 1601-1607. 
63. Kwon, O.S.; Park, S.J.; Lee, J.S.; Park, E.; Kim, T.; Park, H.-W.; You, S.A.; Yoon, H.; Jang, J. Multidimensional conducting polymer nanotubes for ultrasensitive chemical nerve agent sensing. Nano Lett. 2012, 12, 2797-2802.

64. Kwon, O.S.; Park, S.J.; Park, H.-W.; Kim, T.; Kang, M.; Jang, J.; Yoon, H. Kinetically controlled formation of multidimensional poly(3,4-ethylenedioxythiophene) nanostructures in vapordeposition polymerization. Chem. Mater. 2012, 24, 4088-4092.

65. Lee, J.E.; Shim, H.W.; Kwon, O.S.; Huh, Y.-I.; Yoon, H. Real-time detection of metal ions using conjugated polymer composite papers. Analyst 2014, 139, 4466-4475.

66. Lee, J.E.; Lee, Y.; Ahn, K.-J.; Huh, J.; Shim, H.W.; Sampath, G.; Im, W.B.; Huh, Y.-I.; Yoon, H. Role of co-vapors in vapor deposition polymerization. Sci. Rep. 2015, 5, 8420, doi:10.1038/srep08420.

67. Chang, M.; Kim, T.; Park, H.-W.; Kang, M.; Reichmanis, E.; Yoon, H. Imparting chemical stability in nanoparticulate silver via a conjugated polymer casing approach. ACS Appl. Mater. Interfaces 2012, 4, 4357-4365.

68. Wei, W.; Cui, X.; Chen W.; Ivey, D.G. Manganese oxide-based materials as electrochemical supercapacitor electrodes. Chem. Soc. Rev. 2011, 40, 1697-1721.

69. Zhang, S.W.; Chen, G.Z. Manganese oxide based materials for supercapacitors. Energy Mater. 2008, 3, 186-200.

70. Sarkar, D.; Khan, G.G.; Singh, A.K.; Mandal, K. High-performance pseudocapacitor electrodes based on $\alpha-\mathrm{Fe}_{2} \mathrm{O}_{3} / \mathrm{MnO}_{2}$ core-shell nanowire heterostructure arrays. J. Phys. Chem. C 2013, 117, 15523-15531.

71. Muller, G.A.; Cook, J.B.; Kim, H.-S.; Tolbert, S.H.; Dunn, B. High performance pseudocapacitor based on 2D layered metal chalcogenide nanocrystals. Nano Lett. 2015, 15, 1911-1917.

72. Brousse, T.; Toupin, M.; Dugas, R.; Athouël, L.; Crosnier, O.; Bélanger, D. Crystalline $\mathrm{MnO}_{2}$ as possible alternatives to amorphous compounds in electrochemical supercapacitors. J. Electrochem. Soc. 2006, 153, 2171-2180.

73. Ghodbane, O.; Pascal, J.-L.; Favier, F. Microstructural effects on charge-storage properties in $\mathrm{MnO}_{2}$-based electrochemical supercapacitors. ACS Appl. Mater. Interfaces 2009, 1, 1130-1139.

74. Devaraj, S.; Munichandraiah, N. Effect of crystallographic structure of $\mathrm{MnO}_{2}$ on its electrochemical capacitance properties. J. Phys. Chem. C 2008, 112, 4406-4417.

75. Pu, J.; Cui, F.; Chu, S.; Wang, T.; Sheng, E.; Wang, Z. Preparation and electrochemical characterization of hollow hexagonal $\mathrm{NiCo}_{2} \mathrm{~S}_{4}$ nanoplates as pseudocapacitor materials. ACS Sustain. Chem. Eng. 2014, 2, 809-815.

76. Han, J.; Dou, Y.; Zhao, J.; Wei, M.; Evans, D.G.; Duan, X. Flexible CoAl LDH@PEDOT core/shell nanoplatelet array for high-performance energy storage. Small 2013, 9, 98-106.

77. Qiu, T.; Luo, B.; Giersig, M.; Akinoglu, E.M.; Hao, L.; Wang, X.; Shi, L.; Jin, M.; Zhi, L. $\mathrm{Au} @ \mathrm{MnO}_{2}$ core-shell nanomesh electrodes for transparent flexible supercapacitors. Small 2014, $10,4136-4141$.

78. Zhou, C.; Zhang, Y.; Li, Y.; Liu, J. Construction of high-capacitance 3D CoO@polypyrrole nanowire array electrode for aqueous asymmetric supercapacitor. Nano Lett. 2013, 13, 2078-2085.

79. Bai, M.-H.; Bian, L.-J.; Song, Y.; Liu, X.-X. Electrochemical codeposition of vanadium oxide and polypyrrole for high-performance supercapacitor with high working voltage. ACS Appl. Mater. Interfaces 2014, 6, 12656-12664. 
80. Chen, K.; Xue, D. Room-temperature chemical transformation route to $\mathrm{CuO}$ nanowires toward high-performance electrode materials. J. Phys. Chem. C 2013, 117, 22576-22583.

81. Yang, Y.; Li, L.; Ruan, G.; Fei, H.; Xiang, C.; Fan, X.; Tour, J.M. Hydrothermally formed three-dimensional nanoporous $\mathrm{Ni}(\mathrm{OH})_{2}$ thin-film supercapacitors. ACS Nano 2014, 8, 9622-9628.

82. Wang, L.; Lin, C.; Zhang, F.; Jin, J. Phase transformation guided single-layer $\beta-\mathrm{Co}(\mathrm{OH})_{2}$ nanosheets for pseudocapacitive electrodes. ACS Nano 2014, 8, 3724-3734.

83. Deori, K.; Ujjain, S.K.; Sharma, R.K.; Deka, S. Morphology controlled synthesis of nanoporous $\mathrm{Co}_{3} \mathrm{O}_{4}$ nanostructures and their charge storage characteristics in supercapacitors. ACS Appl. Mater. Interfaces 2013, 5, 10665-10672.

84. Liang, J.; Fan, Z.; Chen, S.; Ding, S.; Yang, G. Hierarchical $\mathrm{NiCo}_{2} \mathrm{O}_{4}$ nanosheets@halloysite nanotubes with ultrahigh capacitance and long cycle stability as electrochemical pseudocapacitor materials. Chem. Mater. 2014, 26, 4354-4360.

85. Ye, S.; Feng, J.; Wu, P. Deposition of three-dimensional graphene aerogel on nickel foam as a binder-free supercapacitor electrode. ACS Appl. Mater. Interfaces 2013, 5, 7122-7129.

86. Guan, C.; Zeng, Z.; Li, X.; Cao, X.; Fan, Y.; Xia, X.; Pan, G.; Zhang, H.; Fan, H.J. Atomic-layer-deposition-assisted formation of carbon nanoflakes on metal oxides and energy storage application. Small 2014, 10, 300-307.

87. Emmett, R.K.; Karakaya, M.; Podila, R.; Arcila-Velez, M.R.; Zhu, J.; Rao, A.M.; Roberts, M.E. Can faradaic processes in residual iron catalyst help overcome intrinsic EDLC limits of carbon nanotubes? J. Phys. Chem. C 2014, 118, 26498-26503.

88. Moosavifard, S.E.; El-Kady, M.F.; Rahmanifar, M.S.; Kaner, R.B.; Mousavi, M.F. Designing 3D highly ordered nanoporous $\mathrm{CuO}$ electrodes for high-performance asymmetric supercapacitors. ACS Appl. Mater. Interfaces 2015, 7, 4851-4860.

89. Ghosh, D.; Giri, S.; Das, C.K. Preparation of CTAB-assisted hexagonal platelet $\mathrm{Co}(\mathrm{OH})_{2} /$ graphene hybrid composite as efficient supercapacitor electrode material. ACS Sustain. Chem. Eng. 2013, 1, 1135-1142.

90. Kim, M.; Lee, C.; Jang, J. Fabrication of highly flexible, scalable, and high-performance supercapacitors using polyaniline/reduced graphene oxide film with enhanced electrical conductivity and crystallinity. Adv. Funct. Mater. 2014, 24, 2489-2499.

91. Kotal, M.; Thakur, A.K.; Bhowmick, A.K. Polyaniline-carbon nanofiber composite by a chemical grafting approach and its supercapacitor application. ACS Appl. Mater. Interfaces 2013, 5, 8374-8386.

92. Haq, A.U.; Lim, J.; Yun, J.M.; Lee, W.J.; Han, T.H.; Kim, S.O. Direct growth of polyaniline chains from N-doped sites of carbon nanotubes. Small 2013, 9, 3829-3833.

93. Liu, T.; Finn, L.; Yu, M.; Wang, H.; Zhai, T.; Lu, X.; Tong, Y.; Li, Y. Polyaniline and polypyrrole pseudocapacitor electrodes with excellent cycling stability. Nano Lett. 2014, 14, 2522-2527.

94. Oliveira, H.P.; Sydlik, S.A.; Swager, T.M. Supercapacitors from free-standing polypyrrole/graphene nanocomposites. J. Phys. Chem. C 2013, 117, 10270-10276.

95. Chen, H.; Zhou, S.; Wu, L. Porous nickel hydroxide-manganese dioxide-reduced graphene oxide ternary hybrid spheres as excellent supercapacitor electrode materials. ACS Appl. Mater. Interfaces 2014, 6, 8621-8630.

96. Zhu, J.; Jiang, J.; Sun, Z.; Luo, J.; Fan, Z.; Huang, X.; Zhang, H.; Yu, T. 3D carbon/cobalt-nickel mixed-oxide hybrid nanostructured arrays for asymmetric supercapacitors. Small 2014, 10, 2937-2945. 
97. Long, C.; Qi, D.; Wei, T.; Yan, J.; Jiang, L.; Fan, Z. Nitrogen-doped carbon networks for high energy density supercapacitors derived from polyaniline coated bacterial cellulose. Adv. Funct. Mater. 2014, 24, 3953-3961.

98. Wang, F.; Zhan, X.; Cheng, Z.; Wang, Z.; Wang, Q.; Xu, K.; Safdar, M.; He, J. Tungsten oxide@polypyrrole core-shell nanowire arrays as novel negative electrodes for asymmetric supercapacitors. Small 2015, 11, 749-755.

99. Li, L.; Zhang, Y.; Shi, F.; Zhang, Y.; Zhang, J.; Gu, C.; Wang, X.; Tu, J. Spinel manganese-nickel-cobalt ternary oxide nanowire array for high-performance electrochemical capacitor applications. ACS Appl. Mater. Interfaces 2014, 6, 18040-18047.

100. Lee, J.E.; Park, S.J.; Kwon, O.S.; Shim, H.W.; Jang, J.; Yoon, H. Systematic investigation on charge storage behaviour of multidimensional poly(3,4-ethylenedioxythiophene) nanostructures. RSC Adv. 2014, 4, 37529-37535.

101. Zhao, Y.; Ran, W.; He, J.; Huang, Y.; Liu, Z.; Liu, W.; Tang, Y.; Zhang, L.; Gao, D.; Gao, F. High-performance asymmetric supercapacitors based on multilayer $\mathrm{MnO}_{2}$ /graphene oxide nanoflakes and hierarchical porous carbon with enhanced cycling stability. Small 2015, 11, 1310-1319.

102. Sumboja, A.; Foo, C.Y.; Wang, X.; Lee, P.S. Large areal mass, flexible and free-standing reduced graphene oxide/manganese dioxide paper for asymmetric supercapacitor device. Adv. Mater. 2013, 25, 2809-2815.

103. Xu, D.; Xu, Q.; Wang, K.; Chen, J.; Chen, Z. Fabrication of free-standing hierarchical carbon nanofiber/graphene oxide/polyaniline films for supercapacitors. ACS Appl. Mater. Interfaces 2014, 6, 200-209.

104. Yan, Z.; Ma, L.; Zhu, Y.; Lahiri, I.; Hahm, M.G.; Liu, Z.; Yang, S.; Xiang, C.; Lu, W.; Peng, Z.; et al. Three-dimensional metal-graphene-nanotube multifunctional hybrid materials. ACS Nano 2013, 7, 58-64.

105. Li, Y.; Zhao, X.; Yu, P.; Zhang, Q. Oriented arrays of polyaniline nanorods grown on graphite nanosheets for an electrochemical supercapacitor. Langmuir 2013, 29, 493-500.

106. Ye, S.; Feng, J. Self-assembled three-dimensional hierarchical graphene/polypyrrole nanotube hybrid aerogel and its application for supercapacitors. ACS Appl. Mater. Interfaces 2014, 6, 9671-9679.

107. Yu, Z.; Tetard, L.; Zhai, L.; Thomas, J. Supercapacitor electrode materials: Nanostructures from 0 to 3 dimensions. Energy Environ. Sci. 2015, 8, 702-730.

108. Yu, X.; Lu, B.; Xu, Z. Super long-life supercapacitors based on the construction of nanohoneycomb-like strongly coupled $\mathrm{CoMoO}_{4}-3 \mathrm{D}$ graphene hybrid electrodes. Adv. Mater. 2014, 26, 1044-1051.

109. Wang, W.; Guo, S.; Bozhilov, K.N.; Yan, D.; Ozkan, M.; Ozkan, C.S. Intertwined nanocarbon and manganese oxide hybrid foam for high-energy supercapacitors. Small 2013, 9, 3714-3721.

110. Yu, C.; Ma, P.; Zhou, X.; Wang, A.; Qian, T.; Wu, S.; Chen, Q. All-solid-state flexible supercapacitors based on highly dispersed polypyrrole nanowire and reduced graphene oxide composites. ACS Appl. Mater. Interfaces 2014, 6, 17937-17943. 
111. Chi, K.; Zhang, Z.; Xi, J.; Huang, Y.; Xiao, F.; Wang, S.; Liu, Y. Freestanding graphene paper supported three-dimensional porous graphene-polyaniline nanocomposite synthesized by inkjet printing and in flexible all-solid-state supercapacitor. ACS Appl. Mater. Interfaces 2014, 6, 16312-16319.

112. Meng, Y.; Wang, K.; Zhang, Y.; Wei, Z. Hierarchical porous graphene/polyaniline composite film with superior rate performance for flexible supercapacitors. Adv. Mater. 2013, 25, 6985-6990.

113. Senthilkumar, S.T.; Selvan, R.K.; Melo, J.S.; Sanjeeviraja, C. High performance solid-state electric double layer capacitor from redox mediated gel polymer electrolyte and renewable tamarind fruit shell derived porous carbon. ACS Appl. Mater. Interfaces 2013, 5, 10541-10550.

114. Kang, M.; Lee, J.E.; Shim, H.W.; Jeong, M.S.; Im, W.B.; Yoon, H. Intrinsically conductive polymer binders for electrochemical capacitor application. RSC Adv. 2014, 4, 27939-27945.

(C) 2015 by the authors; licensee MDPI, Basel, Switzerland. This article is an open access article distributed under the terms and conditions of the Creative Commons Attribution license (http://creativecommons.org/licenses/by/4.0/). 